\title{
Consolidated undrained load-carrying capacity of subsea mudmats under combined loading in six degrees of freedom
}

\author{
X. FENG* and S. GOURVENEC*
}

\begin{abstract}
A generalised framework is presented for predicting the consolidated undrained capacity of rectangular mat foundations on normally consolidated soft clay under combined loading in six degrees of freedom as a function of relative preload and degree of consolidation. Consolidated undrained response is investigated by coupled small-strain finite-element analysis using the modified Cam Clay plasticity constitutive model. Increases in the load-carrying capacity of a foundation under combined loading in six degrees of freedom following vertical preload with subsequent consolidation are demonstrated and quantified. The results are presented as failure envelopes in multi-directional load space and are shown to expand proportionally as a function of degree of consolidation for a given relative preload. A methodology and a set of expressions are provided to predict the shape and size of failure envelopes for rectangular mat foundations for any degree of preloading and consolidation.
\end{abstract}

KEYWORDS: bearing capacity; clays; consolidation; failure; footings/foundations; offshore engineering

\section{INTRODUCTION}

Subsea mat foundations are extensively employed on soft clay seabeds to support subsea infrastructure, such as pipeline end terminations and manifolds (PLETs and PLEMs), for offshore oil and gas developments. The mat foundations for pipeline infrastructure are generally rectangular in plan and installed concurrently with the associated pipelines. The size of mudmat required is determined through comparing the worst-case design loads with the undrained load-carrying capacity based on in situ soil strength; that is, neglecting the effects of consolidation. In reality, several months may elapse between installation of the foundations and operation of the pipelines they support. During this period, the soil beneath the mat foundation will consolidate under the self-weight of the mat and structure it supports. The combined load-carrying capacity of mat foundations during operation of the field will be consequently enhanced by the increase in shear strength of the soil from consolidation. The assessment of the increase of load-carrying capacity of mat foundations due to consolidation is not accounted for in offshore design guidelines (e.g. API, 2011; ISO, 2003) and cannot be simply captured by analytical methods because the increase in shear strength due to preloading is non-uniform across the soil domain.

Most previous research on consolidation beneath shallow foundations has focused on elastic consolidation under strip and circular shallow foundations (e.g. Davis \& Poulos, 1968; Booker \& Small, 1986; Gourvenec \& Randolph, 2010), such that capacity cannot be addressed; or elasto-plastic consolidation (e.g. Manoharan \& Dasgupta, 1995; Sloan \& Abbo, 1999; Nazem et al., 2008). Total stress analyses were carried out by Taylor \& Oort (1971) to investigate the increase in bearing capacity resulting from complete consolidation for a uniformly loaded strip foundation. To date, coupling of consolidation and soil yielding, in order to assess consolidated undrained capacity of shallow foundations, has received limited attention.

Manuscript received 23 May 2014; revised manuscript accepted 24 February 2015. Published online ahead of print 16 June 2015. Discussion on this paper closes on 1 December 2015, for further details see p. ii.

* Centre for Offshore Foundation Systems, The University of Western Australia, Crawley, WA, Australia.
The undrained inclined load capacity of a surface strip foundation after consolidation under vertical preloading using coupled small-strain finite-element analysis was investigated by Bransby (2002). The results reveal that both the undrained vertical and horizontal capacities are significantly improved after long-term vertical loading and the shape of the consolidated undrained $\mathrm{V}-\mathrm{H}$ failure envelope is similar to the shape of the undrained $\mathrm{V}-H$ envelope. A work-hardening law was suggested, linking the increase in foundation capacity with the magnitude of the settlement during consolidation under preload. The effects of preloading and full primary consolidation on the undrained vertical bearing capacity of a surface strip foundation on soil with a range of over-consolidation ratios (OCRs) were investigated by Zdravkovic et al. (2003). The analyses indicated that greatest gains were achieved in normally consolidated deposits compared with overconsolidated deposits, which is to be expected since normally consolidated deposits have the greatest potential for reduction in void ratio, and hence gain in shear strength. A systematic study of gain in consolidated undrained vertical bearing capacity of surface strip and circular foundations on deposits with a range of OCRs as a function of relative preload and degree of consolidation (i.e. not just full primary consolidation as in previous studies) was presented by Gourvenec et al. (2014). Gourvenec et al. (2014) also present a theoretical framework based on critical state soil mechanics for predicting the consolidated undrained vertical bearing capacity of surface strip and circular foundations for a range of OCRs as a function of the relative magnitude and duration of preload. Predictions using the theoretical framework compare well with geotechnical centrifuge results of consolidated gains in vertical capacity of a surface foundation on normally consolidated clay (Vulpe \& White, 2014). The theoretical framework was illustrated for predicting gains in undrained vertical bearing capacity by Gourvenec et al. (2014), although the general theoretical framework is applicable to predicting gains in undrained capacity under multi-directional loading and can be applied to boundary value problems other than shallow foundations. For example, the theoretical framework has been successfully applied to predicting gains in lateral break-out resistance of submarine pipelines as a result of relative vertical preload and degree of consolidation (Chatterjee et al., 2014).

External loads transferred to subsea mat foundations are generally in six degrees of freedom, involving vertical load 
$(V)$, biaxial horizontal loads $\left(H_{x}, H_{y}\right)$, biaxial moments $\left(M_{x}, M_{y}\right)$ and torsion $\left(T_{z}\right)$, referred to subsequently as $V-H^{2}-$ $M^{2}-T_{z}$ loading (Fig. 1). The six-degree-of-freedom undrained ultimate limit state of subsea rectangular mat foundations was systematically studied by Feng et al. (2014), resulting in a set of approximating expressions for predicting uniaxial and combined ultimate limit states for a range of foundation embedment ratios and soil strength profiles. This study extends that work to capture the effects of consolidation under preload on the undrained uniaxial and combined load-carrying capacity of rectangular mat foundations in six degrees of freedom.

This study used small-strain finite-element analysis and the modified Cam Clay plasticity soil model to couple the effects of consolidation and soil strength gain to quantify the gain in capacity of rectangular mat foundations. A surface rectangular mat foundation on a normally consolidated soil is considered, with the effect of relative magnitude of preload and degree of consolidation systematically investigated. The theoretical framework for predicting gains in consolidated undrained capacity presented by Gourvenec et al. (2014) is extended to predict the consolidated undrained load-carrying capacity of rectangular mat foundations under combined loading in six degrees of freedom.

\section{FINITE-ELEMENT MODEL}

All of the calculations were carried out using the Abaqus (v. 6.10) program (Dassault Systèmes, 2010).

\section{Model description}

A rigid, impermeable, surface rectangular mat foundation with a breadth-to-length ratio, $B / L=0.5$ was considered. This aspect ratio is typical for subsea mat foundations and is governed by the configuration of the opening on a pipelaying vessel through which the mat foundations, attached to the pipeline, are lowered to the seabed. The breadth of foundation was taken as $B=5 \mathrm{~m}$ for all analyses (typical of field conditions), but results are presented as normalised quantities such that the actual dimension of the foundation is not relevant.

In practice, mat foundations are typically equipped with short 'skirts' that penetrate into the seabed confining a plug of soil leading to a rough, soil-soil, interface at foundation level and potential for tensile resistance due to passive suction developed within the soil plug (provided the foundation is 'sealed', i.e. impermeable). Therefore, the interface between the underside of the mat foundation and the subsoil was taken to be rough in shear with no detachment permitted (i.e. fully bonded) to represent field conditions. The shallowly embedded mat foundation was idealised as a surface foundation with a full tension interface to conceptually represent the presence of skirts, as commonly adopted (e.g. Tani \& Craig, 1995; Bransby \& Randolph, 1998; Taiebat \& Carter, 2000; Gourvenec \& Randolph, 2003). The idealisation is not

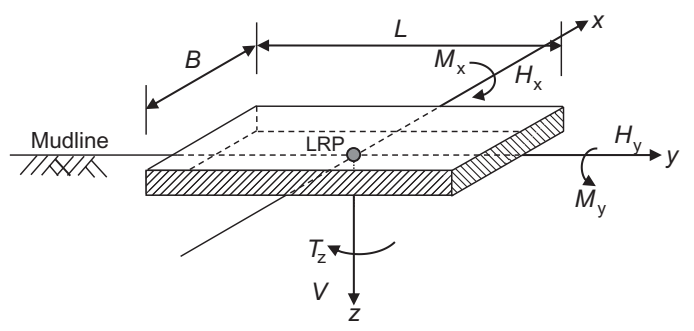

Fig. 1. General loading for a rectangular mat foundation expected to affect the underlying mechanisms accompanying failure, but can underestimate capacity by neglecting the work done by shearing in the soil above skirt tip level.

An example of a finite-element mesh used in this study is shown in Fig. 2. The mesh boundaries extended a distance of $3 B$ from the edges of the foundation and $3 B$ beneath the foundation, with horizontally constrained nodes at the vertical sides, and fully constrained nodes at the base. The boundaries were shown to be sufficiently remote so that changes in soil and pore water pressures were not observed at the edges of the mesh and the failure mechanisms were unaffected. Flow was permitted across the free surface of the mesh but not across the sides or base boundaries of the mesh. Flow across the external vertical sides or base of the mesh was not expected as zones of excess pore water pressure generation were confined close to the foundation and free surface, remote from the external boundaries.

The foundation was modelled as a weightless, rigid body with a load reference point (LRP) located at the centre of the foundation at mudline level. The soil was represented by first-order full integration stress-pore fluid continuum elements (ref. type C3D8P, in the standard Abaqus library).

\section{Soil parameters}

The critical state soil mechanics (CSSM) model in Abaqus, clay plasticity, was used with model parameters to represent modified Cam Clay (MCC) (Roscoe \& Burland, 1968). The implementation of MCC in Abaqus uses a Mises surface in the $\pi$-plane and associated flow was adopted for the plastic potential by defining the flow stress ratio as unity. The numerical parameters used for the analyses are listed in Table 1. These properties are typical of the kaolin clay used for experimental research at the University of Western Australia (Stewart, 1992). The soil was considered to be $K_{0}$-consolidated, with $K_{0}=1-\sin \phi^{\prime}$, where $\phi^{\prime}$ is the critical state angle of shearing resistance.

A uniform surcharge was applied at the upper soil surface (including across the weightless foundation) to provide a nominal, non-zero value of shear strength at the mudline. A surcharge equivalent to $1 \mathrm{~m}$ of soil was applied, providing a mudline strength, $s_{\mathrm{um}}$, of $4.58 \mathrm{kPa}$ and gradient of strength with depth, $\rho$, of $1.71 \mathrm{kPa} / \mathrm{m}$ with the prescribed conditions, giving a dimensionless heterogeneity factor, $\kappa_{\mathrm{su}}=\rho B / s_{\mathrm{um}}=$ $1 \cdot 875$. The undrained shear strength profile was determined from the MCC input parameters using the expression proposed by Potts \& Zdravkovic (1999).

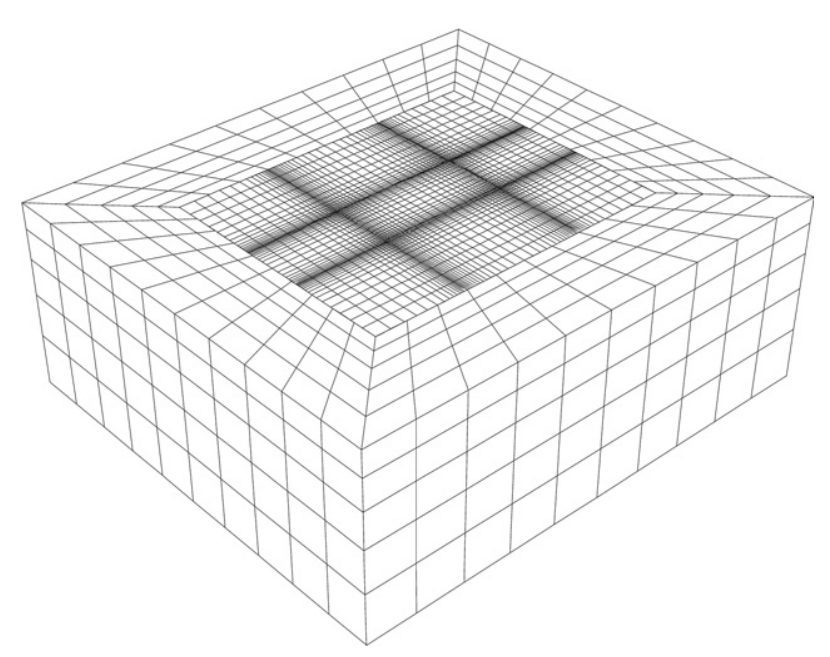

Fig. 2. Finite-element mesh for rectangular mat foundations 
Table 1. Soil parameters for numerical studies

\begin{tabular}{l|l}
\hline Parameter input for finite-element analysis & Values \\
\hline Index and engineering parameters & \\
Saturated bulk unit weight, $\gamma_{\mathrm{sat}}: \mathrm{kN} / \mathrm{m}^{3}$ & $16 \cdot 0$ \\
Permeability of soil, $k: \mathrm{m} / \mathrm{s}$ & $1 \times 10^{-9}$ \\
Unit weight of water, $\gamma_{\mathrm{w}}: \mathrm{kN} / \mathrm{m}^{3}$ & $10 \cdot 0$ \\
Elastic parameters (as a porous elastic & \\
$\quad$ material) & $0 \cdot 044$ \\
Recompression index, $\kappa$ & $0 \cdot 3$ \\
Poisson's ratio, $v^{\prime}$ & 0 \\
Tensile limit & $0 \cdot 205$ \\
Clay plasticity parameters & $0 \cdot 92\left(\phi^{\prime}=23 \cdot 5^{\circ}\right)$ \\
Virgin compression index, $\lambda$ & $1 \cdot 0$ \\
Stress ratio at critical state, $M_{q}=q / p^{\prime}$ & $1 \cdot 0$ \\
Wet yield surface size, $\beta$ & $2 \cdot 14$ \\
Flow stress ratio, $K$ & \\
Intercept on critical state line $(\mathrm{CSL})$, & \\
$\quad e_{\mathrm{cs}}\left(\right.$ at $\left.p^{\prime}=1\right)$ &
\end{tabular}

$$
\frac{s_{\mathrm{u}}}{\sigma_{\mathrm{v}}^{\prime}}=g(\Theta) \cos \Theta \frac{1+2 K_{0}}{3}\left(\frac{1+a^{2}}{2}\right)^{1-(\kappa / \lambda)}
$$

where

$$
\begin{aligned}
g(\Theta) & =\frac{\sin \phi^{\prime}}{\cos \Theta+(1 / \sqrt{3}) \sin \phi^{\prime} \sin \Theta} \\
a & =\frac{\sqrt{3}\left(1-K_{0}\right)}{\boldsymbol{g}\left(-30^{\circ}\right)\left(1+2 K_{0}\right)}
\end{aligned}
$$

with $\Theta$ being the Lode's angle.

All results are normalised by the mudline strength so the absolute values of mudline strength and gradient of shear strength selected in these analyses are irrelevant. The initial soil state throughout the domain is normally consolidated such that any stress increase resulting from the foundation load leads to plastic deformation, as is relevant for soft, normally consolidated deepwater marine deposits.

\section{Scope and loading method}

After establishing the in situ stress condition, a vertical displacement was applied instantaneously to the foundation to identify the unconsolidated, undrained, vertical bearing capacity, $V_{\mathrm{u}}$. Subsequent analyses were performed, in which the foundation was first preloaded to a proportion of $V_{\mathrm{u}}$, defined the relative preload, $V_{\mathrm{p}} / V_{\mathrm{u}}$, within a short duration, preventing any dissipation of excess pore pressure. Subsequently, the preload was held constant and dissipation of the excess pore water pressure that developed due to the preloading was permitted. The soil was then brought to failure under an undrained displacement load path (vertical, translational or rotational) to determine the consolidated, undrained uniaxial capacity, including $V_{\text {u,cons_max }}$, $H_{x \mathrm{u}, \mathrm{cons} \_\max }, H_{y \mathrm{u} \text {,cons_max }}, M_{x \mathrm{u}, \mathrm{cons} \_\max }, M_{y \mathrm{u}, \mathrm{cons} \_\max }$ and $T_{z \mathrm{u}, \mathrm{cons} \_ \text {max }}$. Further analyses considering intermediate degrees of consolidation followed the same principal steps, including establishment of the initial geostatic stress state; preloading of the soil beneath the foundation under an operative vertical load, $V_{\mathrm{p}}$; consolidation over a given duration to achieve the target degree of consolidation; and identification of the consolidated, undrained, load-carrying capacity. Combined load-carrying capacity was determined from sideswipe and constant-ratio displacement-controlled probe tests (e.g. Tan, 1990; Bransby \& Randolph, 1998; Gourvenec \& Randolph, 2003) under undrained conditions and presented in the form of failure envelopes. Displacementcontrolled 'swipe' loading paths have been shown to closely follow the failure envelopes only for surface foundations in the $V-H, V-M$ and $V-T_{z}$ loading planes. Displacement-controlled probe tests were carried out for all other load and foundation conditions. Only a single point can be provided on the failure envelope by a fixed displacement ratio probe test and failure is defined where the normal to the load path matches the prescribed displacement ratio in accordance with the associated flow rule.

In engineering practice, the self-weight of mat foundations and the pipeline structure they support generally mobilises less than $50 \%$ of the unconsolidated, undrained, vertical bearing capacity, $V_{\mathrm{u}}$. In contrast to many shallow foundation applications onshore and offshore, design of subsea shallow foundations is governed by $H-M-T_{z}$ capacity rather than vertical capacity. The relative preloading considered in this study was therefore prescribed to span $10 \%$ to $70 \%$ of the unconsolidated, undrained, vertical bearing capacity, namely $V_{\mathrm{p}} / V_{\mathrm{u}}$, in increments of $10 \%$. The consolidation period was prescribed as a percentage of the time for completion of full primary consolidation, $T_{99}$, in increments of $10 \%$, namely $T_{10}, T_{20}$ and so on, representing the time for $10 \%$ and $20 \%$ of full primary consolidation to occur.

\section{RESULTS}

Unconsolidated, undrained, uniaxial capacities and model validation

The unconsolidated, undrained, vertical capacity from this study gives $V_{\mathrm{u}} / A s_{\mathrm{um}}=7 \cdot 56$, which is $1 \cdot 5 \%$ greater than the value of $V_{\mathrm{u}} / A s_{\mathrm{um}}=7 \cdot 45$ calculated by classical bearing capacity theory as proposed in the API guidelines (API, 2011). Horizontal capacity, $H_{x \mathrm{u}} / A s_{\mathrm{um}}=1.04$ and $H_{y \mathrm{u}} / A s_{\mathrm{um}}=1 \cdot 03$, compares well with the theoretical value of $H_{\mathrm{u}} / A s_{\mathrm{um}}=1.0$ from a pure sliding mechanism of a surface foundation. The slight overestimation arises from shearing in the uppermost soil element of small but finite depth as opposed to across the essentially zero-thickness foundationsoil interface. As for the moment capacity, the factors of $M_{y \mathrm{u}} / A B s_{\mathrm{um}}$ and $M_{x \mathrm{u}} / A L s_{\mathrm{um}}$ from current analysis are $1 \cdot 10$ and $1 \cdot 50$, respectively. No analytical solutions exist for comparison, but the results compare well with the previous undrained Tresca finite-element results obtained by Feng et al. (2014), which gave $M_{y \mathrm{u}} / A B s_{\mathrm{um}}=1 \cdot 13$ and $M_{x \mathrm{u}} / A L s_{\mathrm{um}}=1 \cdot 53$. The undrained torsional capacity of $T_{z \mathrm{u}} / A L s_{\mathrm{um}}$ equals $0 \cdot 31$, which is approximately $6 \%$ greater than the analytical solution derived by Murff et al. (2010).

\section{Undrained uniaxial capacities following full primary consolidation}

Normalised vertical load-settlement response to failure following vertical preloading and full primary consolidation is shown in Fig. 3. The unconsolidated (i.e. $V_{\mathrm{p}}=0$ ) undrained

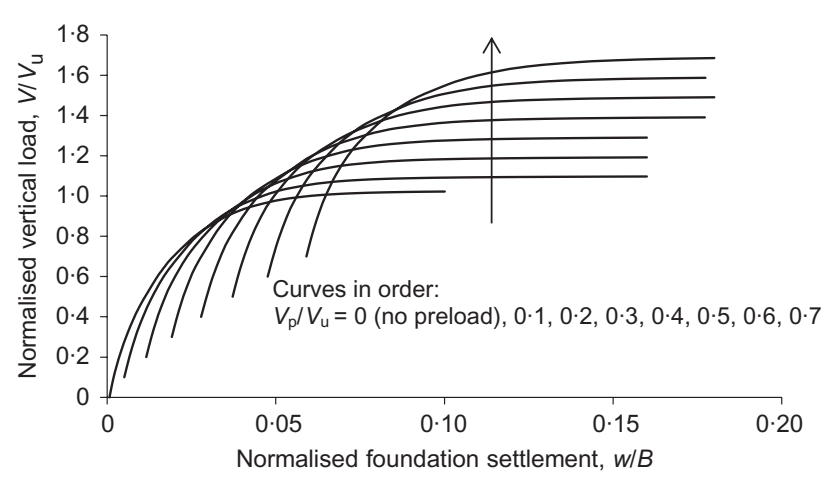

Fig. 3. Normalised vertical load-settlement response to failure following preloading and full primary consolidation 
load-settlement response plateaus at a normalised vertical load, $V / V_{\mathrm{u}}=1$. Undrained vertical bearing capacity following preloading, $V_{\mathrm{p}} / V_{\mathrm{u}}$, and full primary consolidation show gains compared with the unconsolidated undrained case, that is, $V / V_{\mathrm{u}}>1$. The load-settlement response is replotted in Fig. 4 with foundation loads adjusted to remove the magnitude of preload, $\left(V-V_{\mathrm{p}}\right) / V_{\mathrm{u}}$ and shows that the adjusted foundation loads converge to $\left(V-V_{\mathrm{p}}\right) / V_{\mathrm{u}}=1$ for each level of preload. This implies that the relative gain in vertical bearing capacity, $V_{\mathrm{u} \text {,cons_max }} / V_{\mathrm{u}}$, increases proportionally with the relative preload, $V_{\mathrm{p}} / V_{\mathrm{u}}$. This is reasonable, since on initial application of the preload, a bulb of excess pore water pressure is developed within the soil mass, the extent of which is essentially independent of the relative magnitude of the preload. After full primary consolidation, when the excess pore water pressures have dissipated and the distribution of the pore water pressure recovered back to the hydrostatic status, any subsequent vertical loading to mobilise undrained failure of the foundation provokes a virtually identical excess pore pressure bulb to that developed under preloading.

Gain in vertical, biaxial horizontal, biaxial moment and torsional capacity resulting from vertical preloading, $V_{\mathrm{p}} / V_{\mathrm{u}}$, and full primary consolidation is presented in Fig. 5. Greater relative gain was observed in the consolidated horizontal and torsional capacity than that in the vertical and moment capacity. This is because the zone of sliding in a horizontal translation or torsional sliding failure mechanism coincides with the zone of maximum strength increase, directly beneath the foundation. The increase in torsional capacity is greater than the increase in horizontal capacity as the greatest gain in shear strength is around the edges of the (rigid) foundation, which is more involved in the torsional failure mechanism. The enhancement in vertical capacity for a given preload is bracketed by the gain in the biaxial moment capacity

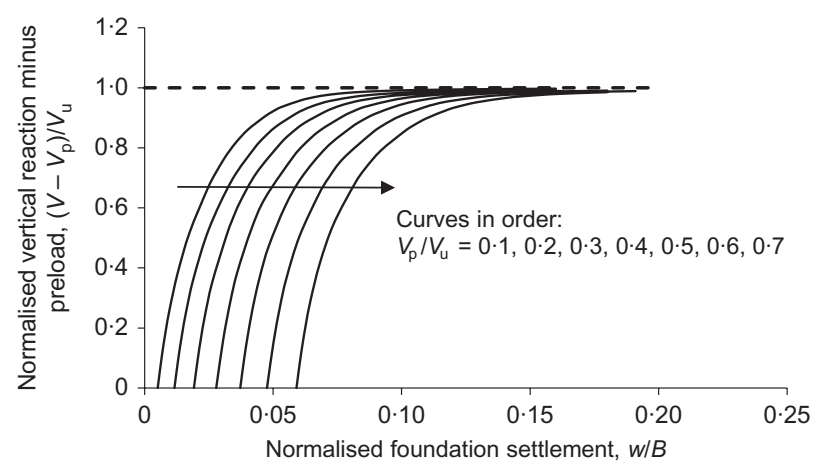

Fig. 4. Normalised incremental vertical load-settlement response to failure following preloading and full primary consolidation

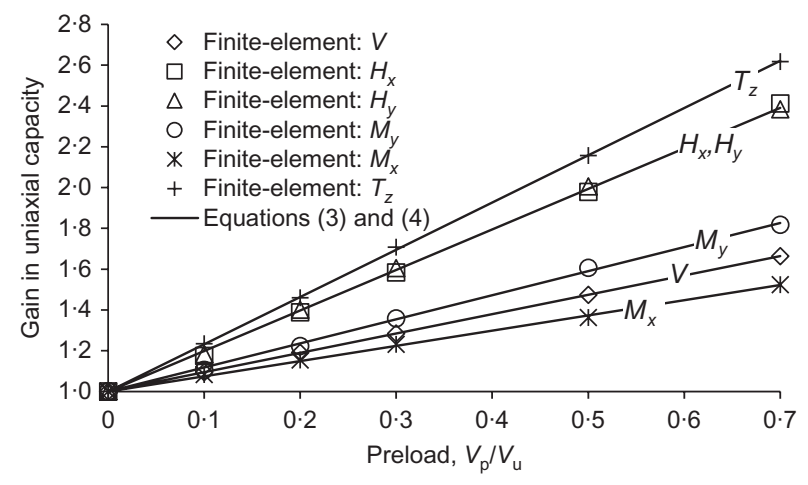

Fig. 5. Observed gain in undrained uniaxial capacity due to preloading and full primary consolidation reflecting the different zones of influence of soil mobilised beneath the foundation. The improvement in the shear strength of the soil after consolidation decreases with depth, leading to less gain in the capacity when the zone of the failure mechanism extends deeper. The depth of the soil failure mechanism for ultimate vertical capacity was in between that for moment capacity along the $x$-axis (the deepest) and the $y$-axis (the shallowest), indicating an intermediate relative gain is to be expected.

A theoretical framework for predicting the gain in undrained vertical bearing capacity of surface strip and circular foundations following vertical preloading and consolidation was proposed by Gourvenec et al. (2014) by linking the preload stress to change in void ratio and hence increase in soil shear strength. For a normally consolidated deposit, incremental plastic stress leads to an increase in strength of $R \Delta \sigma_{\mathrm{pl}}^{\prime}$, where $R$ is the normally consolidated undrained strength ratio, $s_{\mathrm{u}} / \sigma_{\mathrm{v}}^{\prime}$, and $\Delta \sigma_{\mathrm{pl}}^{\prime}$ is the incremental plastic stress relevant to the preload stress, expressed as

$$
\Delta \sigma_{\mathrm{pl}}^{\prime}=f_{\sigma} v_{\mathrm{p}}=f_{\sigma}\left(V_{\mathrm{p}} / A\right)
$$

where $f_{\sigma}$ is a stress factor to account for the non-uniform distribution of stress in the zone of soil affected by the preload and $A$ is the foundation bearing area.

The change in strength due to the preload is therefore given by

$$
\Delta s_{\mathrm{u}}=f_{\mathrm{su}} R \Delta \sigma_{\mathrm{pl}}^{\prime}=f_{\mathrm{su}} f_{\sigma} R\left(V_{\mathrm{p}} / A\right)
$$

where $f_{\text {su }}$ is a shear strength factor to account for the non-uniform distribution of the increase in shear strength and the interaction of the zone of enhanced shear strength and zone of soil involved in a subsequent failure mechanism.

Ultimately, the gain in vertical bearing capacity for a surface foundation can be derived in terms of the gain in operative undrained strength

$$
\frac{V_{\text {u,cons }_{-} \text {max }}}{V_{\mathrm{u}}}=1+\frac{\Delta s_{\mathrm{u}}}{s_{\mathrm{u}}}=1+f_{\sigma} f_{\mathrm{su}} R\left(\frac{V_{\mathrm{p}}}{V_{\mathrm{u}}}\right) N_{\mathrm{cv}}
$$

where $N_{\mathrm{cv}}$ is the unconsolidated undrained vertical bearing capacity factor defined as $V_{\mathrm{u}} / A s_{\mathrm{um}}$. Separate scaling factors, $f_{\sigma}$ and $f_{\text {su }}$, allow the response in overconsolidated conditions to be captured, but in the present normally consolidated conditions there is effectively a single scaling parameter, $f_{a} f_{\text {su }}$ for a particular load path. The approach described by equation (4) for prediction of gains in vertical capacity is similarly applied to other load paths, as outlined in equation (5).

$$
\begin{aligned}
& \frac{H_{x(y) \mathrm{u}, \text { cons_max }_{-}}}{H_{x(y) \mathrm{u}}}=1+\frac{\Delta s_{\mathrm{u}}}{s_{\mathrm{u}}}=1+f_{\sigma} f_{\mathrm{su}} R\left(\frac{V_{\mathrm{p}}}{V_{\mathrm{u}}}\right) N_{\mathrm{cv}} \\
& \frac{M_{x \mathrm{u}, \text { cons_max }}}{M_{x \mathrm{u}}}=1+\frac{\Delta s_{\mathrm{u}}}{s_{\mathrm{u}}}=1+f_{\sigma} f_{\mathrm{su}} R\left(\frac{V_{\mathrm{p}}}{V_{\mathrm{u}}}\right) N_{\mathrm{cv}} \\
& \frac{M_{y \mathrm{u}, \text { cons_max }}}{M_{y \mathrm{u}}}=1+\frac{\Delta s_{\mathrm{u}}}{s_{\mathrm{u}}}=1+f_{\sigma} f_{\mathrm{su}} R\left(\frac{V_{\mathrm{p}}}{V_{\mathrm{u}}}\right) N_{\mathrm{cv}} \\
& \frac{T_{z \mathrm{u}, \text { cons_max }}}{T_{z \mathrm{u}}}=1+\frac{\Delta s_{\mathrm{u}}}{s_{\mathrm{u}}}=1+f_{\sigma} f_{\mathrm{su}} R\left(\frac{V_{\mathrm{p}}}{V_{\mathrm{u}}}\right) N_{\mathrm{cv}}
\end{aligned}
$$

The methodology was applied to the uniaxial gains calculated by the finite-element analyses (presented in Fig. 5) to determine the scaling parameters, $f_{a} f_{\text {su }}$ for rectangular mat foundations under undrained loading in six degrees of freedom, which are summarised in Table 2.

The sensitivity of the scaling parameters, $f_{a} f_{\text {su }}$, for each load path direction was assessed over a practical range of soil parameter values for $\kappa, \lambda, M_{q}$ and $e_{\mathrm{cs}}$. Finite-element analyses 
Table 2. Values of $f_{a} f_{\text {su }}$ for predicting the gain in uniaxial capacities after full primary consolidation

\begin{tabular}{l|l}
\hline Uniaxial capacity & $f_{\sigma} f_{\text {su }}$ \\
\hline Vertical capacity, $V_{\text {u,cons_max }}$ & $0 \cdot 439$ \\
Horizontal capacity along $x$-axis, $H_{x \text { u,cons_max }}$ & $0 \cdot 919$ \\
Horizontal capacity along $y$-axis, $H_{y \text { u,cons_max }}$ & $0 \cdot 919$ \\
Moment capacity about $x$-axis, $M_{x \mathrm{u}, \text { cons_max }}$ & $0 \cdot 345$ \\
Moment capacity about $y$-axis, $M_{y \text { u,cons_max }}$ & $0 \cdot 538$ \\
Torsional capacity, $T_{z \text { u,cons_max }}$ & $1 \cdot 071$ \\
\hline
\end{tabular}

were carried out, in which MCC parameter values were varied in turn, all other things remaining equal. Equation (1) indicates that the normally consolidated, undrained shear strength ratio, $R$, is associated with the value of $\kappa / \lambda$ and $M_{q}$ (or $\phi^{\prime}$ ) but not $e_{\mathrm{cs}}$. Therefore, an identical value of $f_{\sigma} f_{\text {su }}$ can be used for predicting the gains irrespective of the chosen $e_{\mathrm{cs}}$. Even though the value of $R$ changes with varying $\kappa, \lambda$ and $M_{q}$, gains calculated by the finite-element analyses are well predicted using constant scaling parameters, $f_{\sigma} f_{\text {su }}$, as set out in Table 2 for a practical range of MCC material properties. The results are presented graphically in Fig. 6, demonstrating the generality of the theoretical framework.

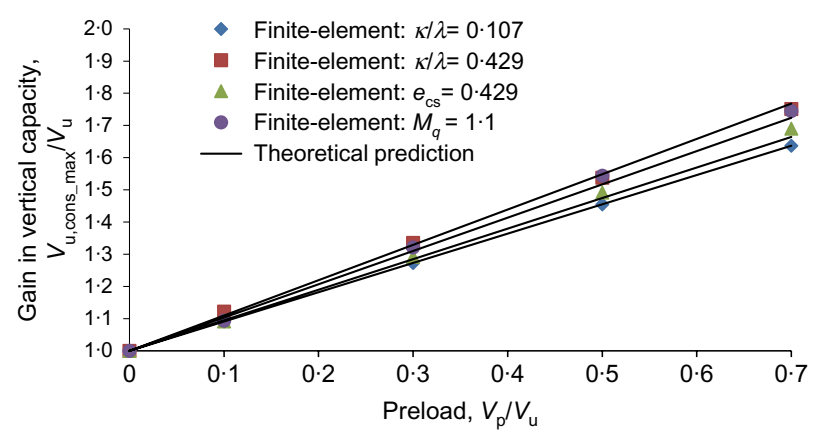

(a)

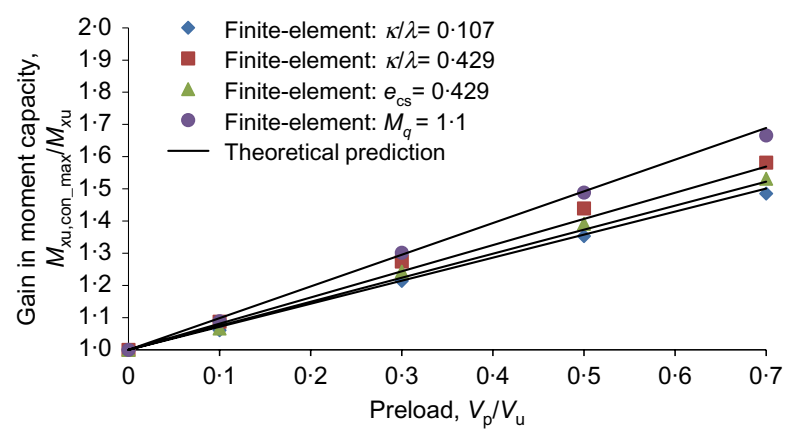

(c)

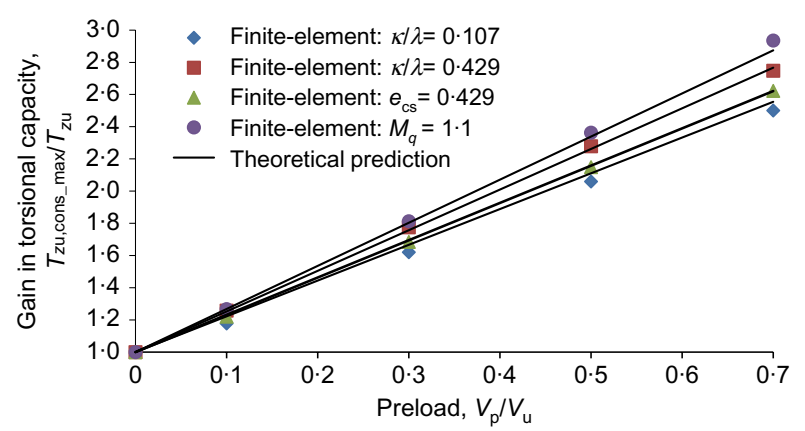

(e)

Fig. 6. Sensitivity of MCC parameters to gain in uniaxial capacity after full primary consolidation and illustration of generality of theoretical prediction: (a) vertical; (b) horizontal; (c) moment, about $x$-axis; (d) moment, about $y$-axis; (e) torsion
Time-settlement histories

Figure 7 shows the log time-settlement response of the foundation for relative preloads at increments of $V_{\mathrm{p}} / V_{\mathrm{u}}=0 \cdot 1$. Only the time-dependent component of settlement is shown in other words, the immediate settlement during load application is deducted from the total settlement. Time is represented by the dimensionless time factor

$$
T=\frac{c_{\mathrm{v} 0} t}{B^{2}}
$$

where $c_{\mathrm{v} 0}$ is the in situ coefficient of consolidation and $t$ is the elapsed time since the start of consolidation. The coefficient is expressed as

$$
c_{\mathrm{v} 0}=\frac{3\left(1+e_{0}\right) p_{0}^{\prime}}{\left(1+2 K_{0}\right)} \frac{k}{\lambda \gamma_{\mathrm{w}}}
$$

where $e_{0}$ is the in situ value of void ratio and $p_{0}^{\prime}$ is the corresponding mean effective normal stress. For simplicity, the mudline value of $c_{\mathrm{v} 0}$ was used for normalisation. dation is independent of the magnitude of preload and can be approximated by a hyperbolic function

$$
U=\frac{w}{w_{\mathrm{f}}}=\frac{1}{1+\left(T / T_{50}\right)^{-m}}
$$

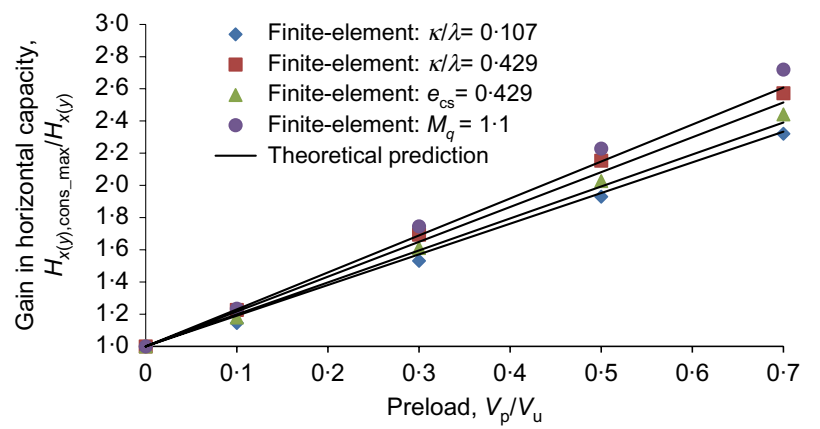

(b)

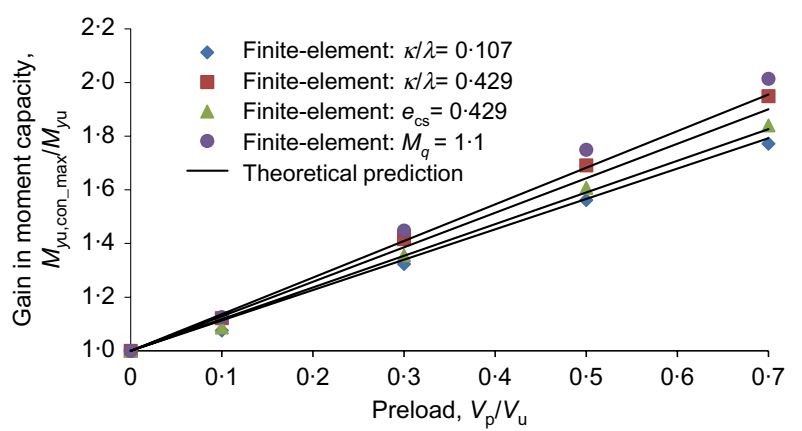

(d)
The normalised time-settlement response of the foun- 
with $T_{50}$ being the dimensionless time factor for $50 \%$ of the consolidation settlement to occur and $m$ being a constant. $T_{50}=0.043$ and $m=1.05$ gave best fit of the finite-element results - similar to the values for the normalised time-

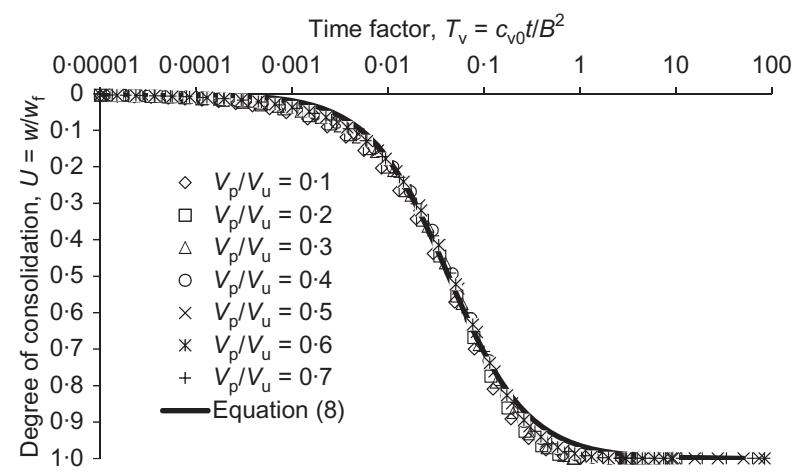

Fig. 7. Normalised time-settlement response of foundation under a range of preload: in situ $c_{\mathrm{v} 0}$

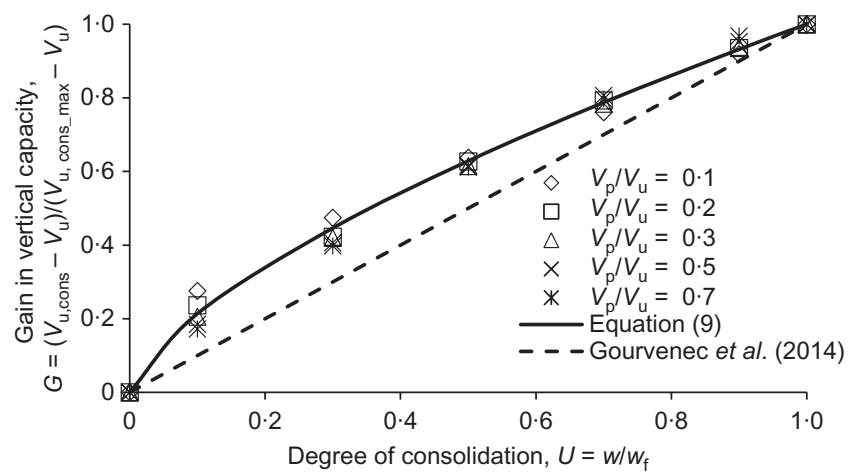

(a)

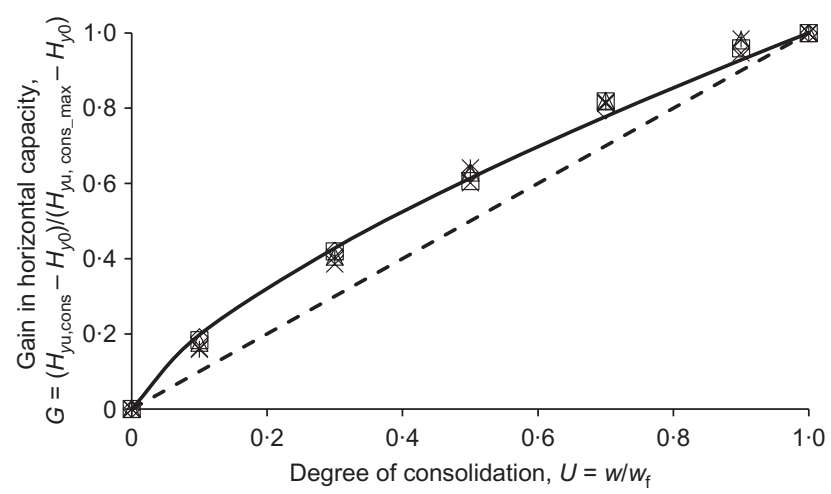

(c)

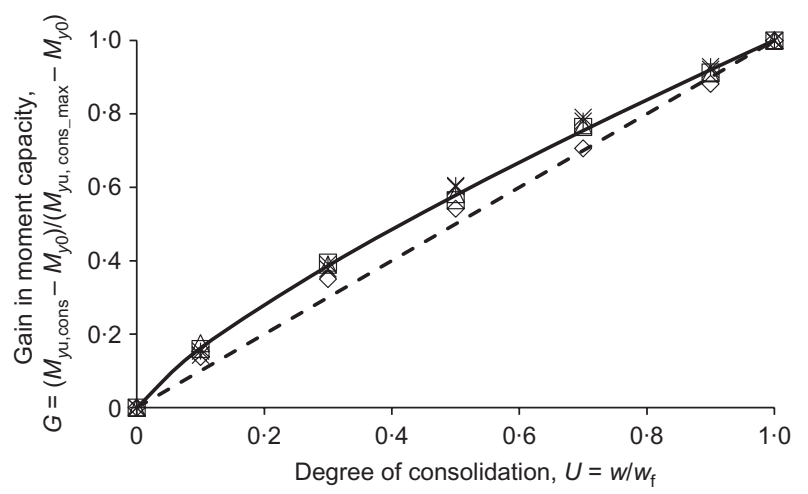

(e) settlement response for a circular surface foundation presented by Gourvenec et al. (2014). Three-dimensional flow and strains significantly affect the rate of consolidation and $T_{50}$ may be an order of magnitude greater under plane strain conditions (Gourvenec et al., 2014). The end of primary consolidation is determined when the time-settlement response of the foundation approaches the plateau.

Undrained uniaxial capacities following partial consolidation

Having established a method of assessing the timesettlement histories under a given relative preload, the gain in the undrained uniaxial capacity considering partial consolidation is introduced. The duration of the applied vertical preload is determined to achieve a proportion of full primary consolidation settlement (defined in increments of $10 \%$ ), after which the undrained response of the foundation is examined. A work-hardening rule may be used for linking the consolidated undrained bearing capacity to consolidation settlement during the preload consolidation stage as suggested by Bransby (2002). As an extension of this notion,

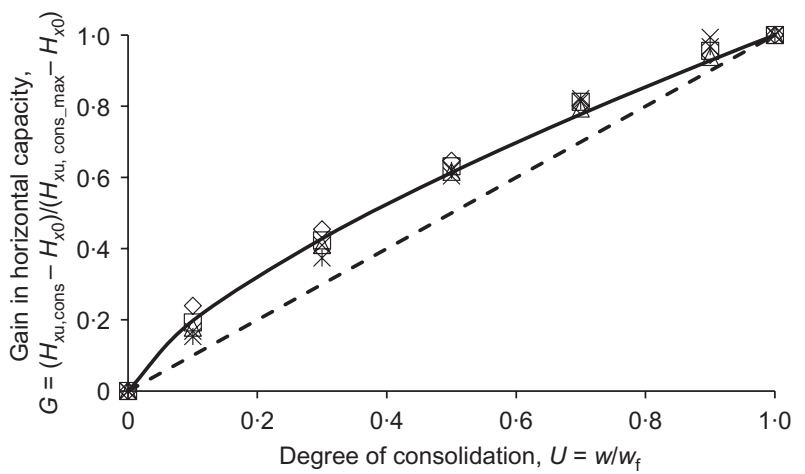

(b)

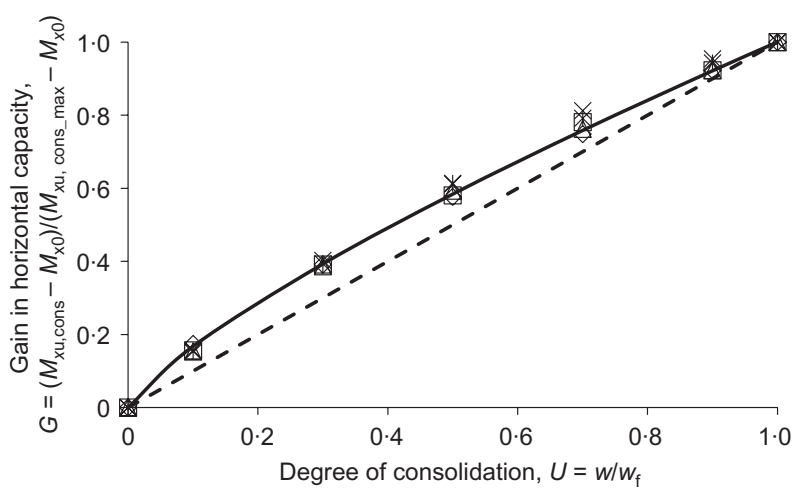

(d)

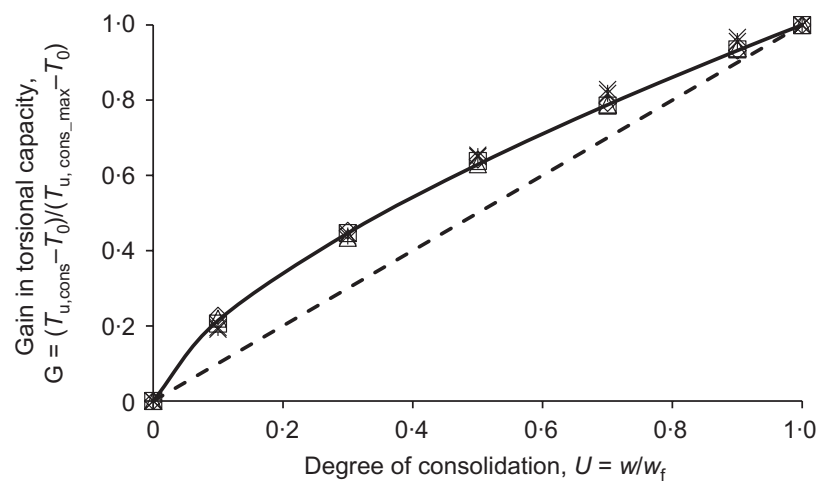

(f)

Fig. 8. Gain in uniaxial capacity as a function of degree of consolidation: (a) vertical; (b) horizontal, along $x$-axis; (c) horizontal, along $y$-axis; (d) moment, about $x$-axis; (e) moment, about $y$-axis; (f) torsion 
Gourvenec et al. (2014) proposed a simple 1:1 relationship between the normalised gain and degree of consolidation to predict a lower limit of the consolidated undrained vertical bearing capacity. In this study, the normalised gains were fitted with a power function to yield more precise fits to the finite-element results (see Fig. 8). The normalised gain in capacity for each load path can be estimated by

$$
\begin{aligned}
& V_{\mathrm{u}, \mathrm{cons}}=U^{g}\left(V_{\mathrm{u}, \text { cons_max }}-V_{\mathrm{u}}\right)+V_{\mathrm{u}} \\
& H_{\mathrm{xu}, \mathrm{cons}}=U^{g}\left(H_{x \mathrm{u}, \text { cons_max }}-H_{x 0}\right)+H_{x 0} \\
& H_{\mathrm{yu}, \mathrm{cons}}=U^{g}\left(H_{y \mathrm{u}, \text { cons_max }}-H_{y 0}\right)+H_{y 0} \\
& M_{\mathrm{xu}, \mathrm{cons}}=U^{g}\left(M_{x \mathrm{u}, \text { cons_max }}-M_{x 0}\right)+M_{x 0} \\
& M_{\mathrm{yu}, \mathrm{cons}}=U^{g}\left(M_{y \mathrm{u}, \text { cons_max }}-M_{y 0}\right)+M_{y 0} \\
& T_{\mathrm{zu}, \text { cons }}=U^{g}\left(T_{z \mathrm{u}, \text { cons_max }}-T_{z 0}\right)+T_{z 0}
\end{aligned}
$$

with $H_{x 0}\left(H_{y 0}\right), M_{x 0}\left(M_{y 0}\right)$ and $T_{z 0}$ being the horizontal, moment and torsional capacity accounting for the mobilised vertical capacity, namely, $V_{\mathrm{p}} / V_{\mathrm{u}}$. The exponent $g$, as listed in Table 3 , is a function of the loading direction.

\section{Consolidated, undrained capacity of mat foundations} under $V-H^{2}-M^{2}-T_{z}$ loading

Following the definition of the uniaxial capacities, the improvement of load-carrying capacity under general $V-H^{2}-M^{2}-T_{z}$ loading is considered by exploring two dimensional slices through the failure envelope.

\section{Combined load capacity including $\mathrm{V}$}

Figure 9(a) shows $V-H_{x}$ failure envelopes after full primary consolidation $\left(t=T_{99}\right)$ for various magnitudes of relative preload, $V_{\mathrm{p}} / V_{\mathrm{u}}$. The innermost envelope corresponds to the unconsolidated, undrained ultimate limit state. An increase in the relative preload, $V_{\mathrm{p}} / V_{\mathrm{u}}$, and the completion of full primary consolidation, that is, $T_{99}$, leads to the expansion of the failure envelopes, reflecting the improvement in the load-carrying capacity. The $V-H_{x}$ failure envelopes under given relative preload, $V_{\mathrm{p}} / V_{\mathrm{u}}=0 \cdot 5$, are plotted in Fig. 9(b) for various consolidation times, $t=T_{10}, T_{50}$ and $T_{90}$, that is, to achieve degrees of consolidation, $U=0.1,0.5$ and 0.9 , showing the effects of duration of preload. The finite-element results indicate that the $V-H_{x}$ failure envelope expands proportionally with the consolidated uniaxial capacities defined as a function of the result of preloading and consolidation - despite the consolidated, undrained shear strength distribution in the vicinity of the foundation altering the optimal failure mechanism somewhat. The $V-H_{y}$ failure envelopes show a similar trend to those in $V-H_{x}$ space (see Fig. 10). Therefore, the $V-H$ failure envelopes can be approximated by the expression proposed by Feng et al. (2014) for unconsolidated, undrained conditions, but with

Table 3. Values of $\boldsymbol{g}$ for predicting the uniaxial capacities after partial consolidation

\begin{tabular}{l|c}
\hline Uniaxial capacity & $g$ \\
\hline Vertical capacity, $V_{\mathrm{u}, \text { cons }}$ & 0.670 \\
Horizontal capacity along $x$-axis, $H_{x \mathrm{u}, \mathrm{cons}}$ & $0 \cdot 705$ \\
Horizontal capacity along $y$-axis, $H_{y \mathrm{u}, \mathrm{cons}}$ & $0 \cdot 705$ \\
Moment capacity about $x$-axis, $M_{x \mathrm{u}, \mathrm{cons}}$ & $0 \cdot 790$ \\
Moment capacity about $y$-axis, $M_{y, \text { cons }}$ & $0 \cdot 776$ \\
Torsional capacity, $T_{z \mathrm{u}, \mathrm{cons}}$ & 0.669 \\
\hline
\end{tabular}

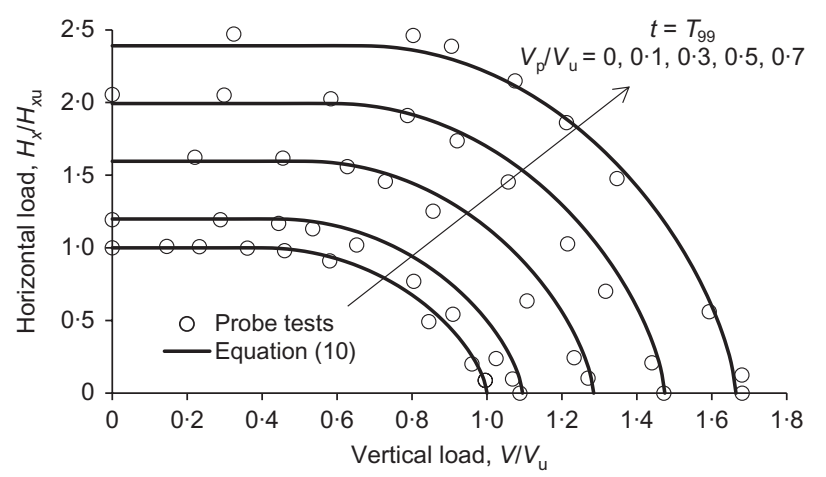

(a)

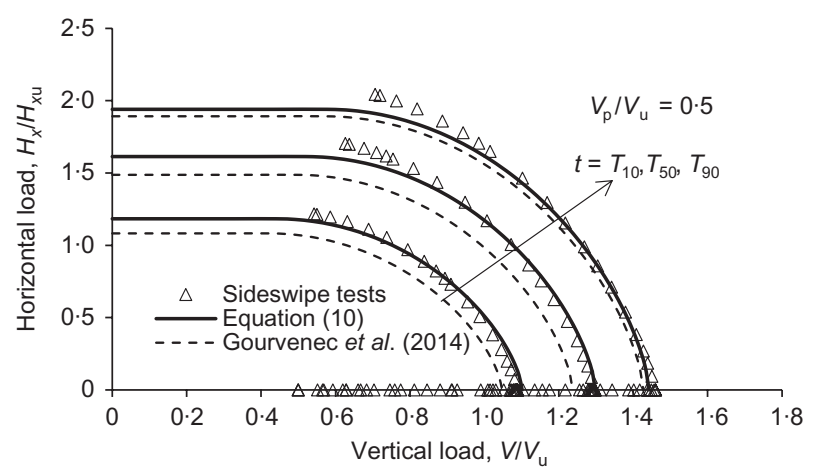

(a)

Fig. 9. Failure envelopes for combined $V-H_{x}$ loading: (a) varying preloads, $t=T_{99}$; (b) differing duration of preloading, $V_{\mathrm{p}} / V_{\mathrm{u}}=0.5$

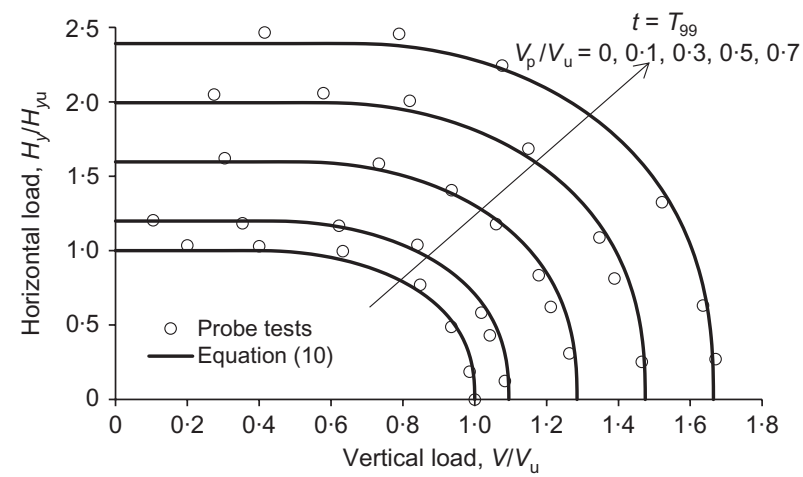

(a)

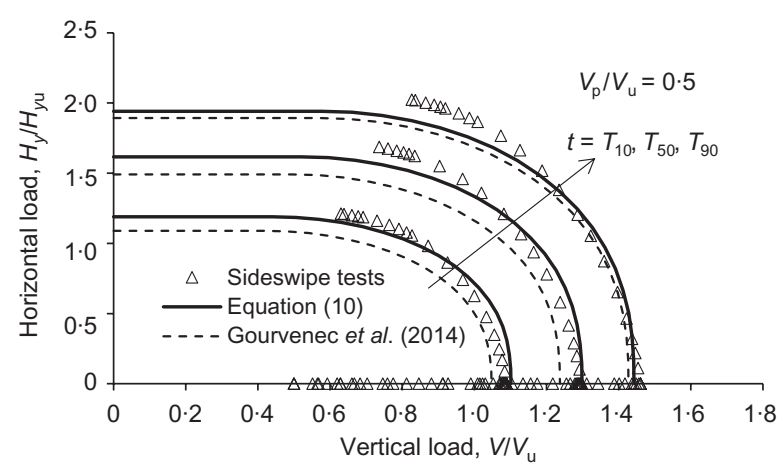

(b)

Fig. 10. Failure envelopes for combined $V-H_{y}$ loading: (a) varying preloads, $t=T_{99} ;$ (b) differing duration of preloading, $V_{\mathrm{p}} / V_{\mathrm{u}}=0.5$

$V$ and $H$ normalised with respect to their corresponding consolidated, undrained capacity as $v=V / V_{\mathrm{u}, \mathrm{cons}}$ and $h=$ $H_{x} / H_{x \mathrm{u} \text {,cons }}$ (for loading angle $\theta=0^{\circ}$ ) or $h=H_{y} / H_{y \mathrm{u}, \mathrm{cons}}$ (for $\theta=90^{\circ}$ ) (see equation (10)). 


$$
\begin{aligned}
& \text { For } v \leq 0.4, h=1 \\
& \text { For } h<1, v=0.4+0.6 \sqrt{1-h^{2 \cdot 5-\cos ^{2} \theta}}
\end{aligned}
$$

The unconsolidated, undrained failure envelopes in $V-M$ and $V-T_{z}$ space are also shown to expand proportionally with the consolidated, undrained uniaxial capacities, defined as a function of relative preload and degree of consolidation.

The normalised $V-M$ failure envelopes (Fig. 11 and Fig. 12) may therefore be fitted by a simple power law curve, proposed for unconsolidated, undrained conditions, (Gourvenec \& Randolph, 2003) of the form

$$
v=(1-m)^{p}
$$

The exponent $p$ depends on the foundation aspect ratio and the degree of strength heterogeneity. For moment loading about the long axis (i.e. the $V-M_{y}$ plane), the exponent was given by Feng et al. (2014) as

$$
\begin{aligned}
p= & 0 \cdot 23\left(1+0 \cdot 19 \kappa_{\mathrm{su}}-0 \cdot 02 \kappa_{\mathrm{su}}^{2}+0 \cdot 001 \kappa_{\mathrm{su}}^{3}\right) \\
& \times\left[1+0 \cdot 4 \frac{B}{L}-0 \cdot 1\left(\frac{B}{L}\right)^{2}\right]
\end{aligned}
$$

For moment loading about the short axis ( $V-M_{x}$ plane) the same power law expression can be used, but replacing $B / L$ by $L / B$. The curve fitting undercuts the gain in $V-M$ loadcarrying capacity for cases of $V_{\mathrm{p}} / V_{\mathrm{u}}>0.3$ since the underprediction of the gain in pure moment capacity becomes more significant with increasing vertical load mobilisation.

The failure envelopes under combined $V-T_{z}$ loading, expressed as equation (13), are shown against the finite-element results in Fig. 13.

$$
\begin{aligned}
& \text { For } v \leq 0 \cdot 5, \quad t_{z}=1 \\
& \text { For } t_{z}<1, \quad v=0 \cdot 5+0 \cdot 5 \sqrt{1-t_{z}^{2 \cdot 5}}
\end{aligned}
$$

where $t_{z}=T_{z} / T_{z \mathrm{u}, \mathrm{cons}}$

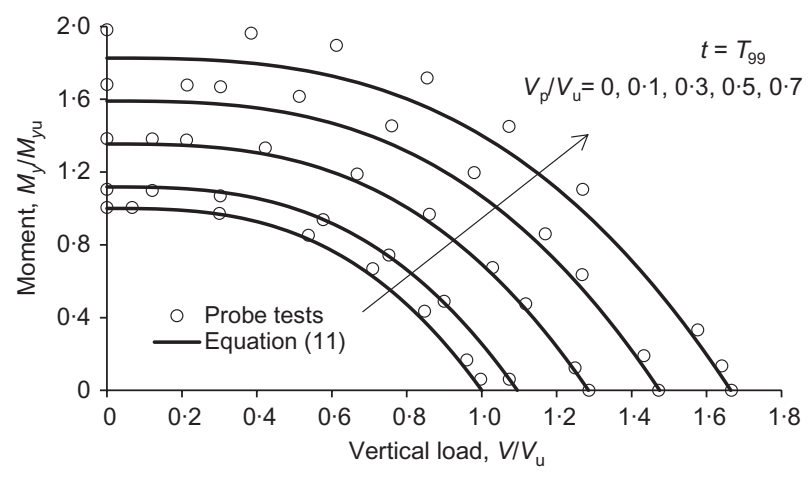

(a)

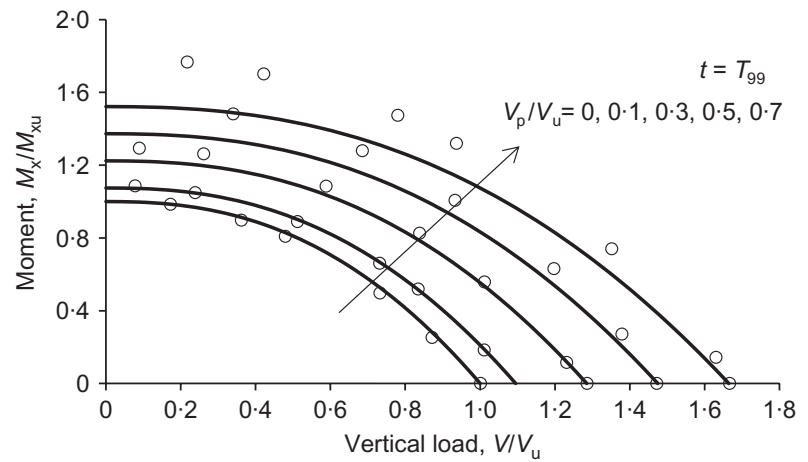

(b)

Fig. 11. Effect of magnitude of preload on $V-M$ failure envelopes: (a) $V-M_{y}$ failure envelopes: (b) $V-M_{x}$ failure envelopes

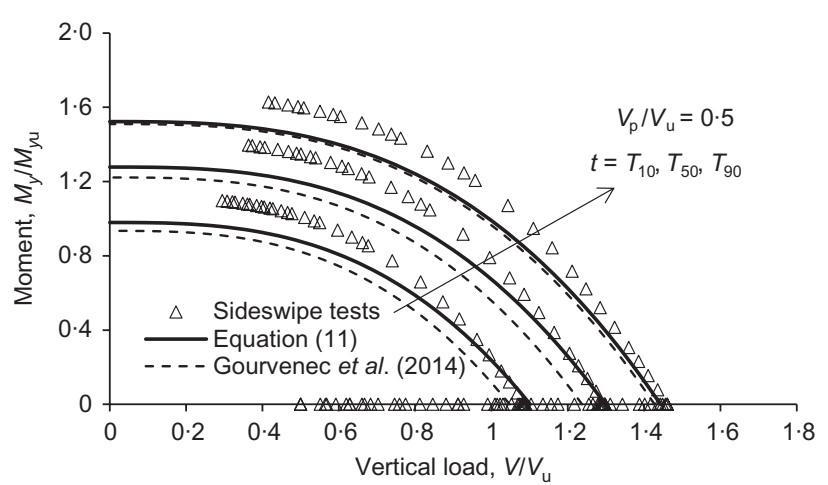

(a)

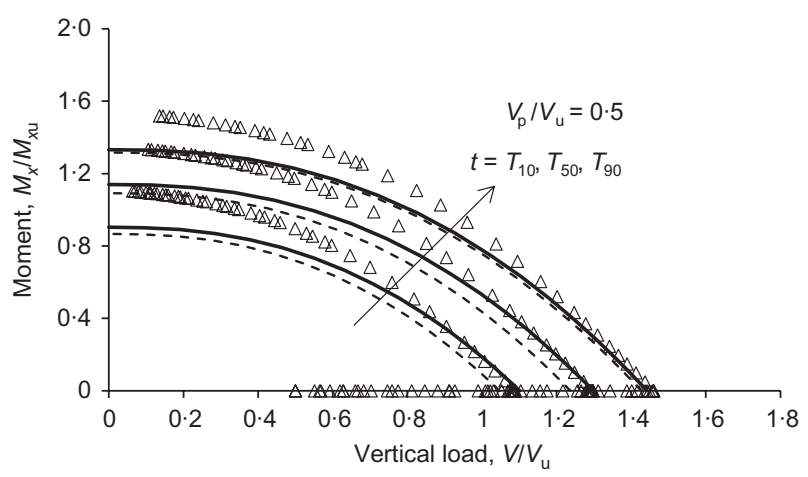

(b)

Fig. 12. Effect of duration of preload on $V-M$ failure envelopes: (a) $V-M_{y}$ failure envelopes: (b) $V-M_{x}$ failure envelopes

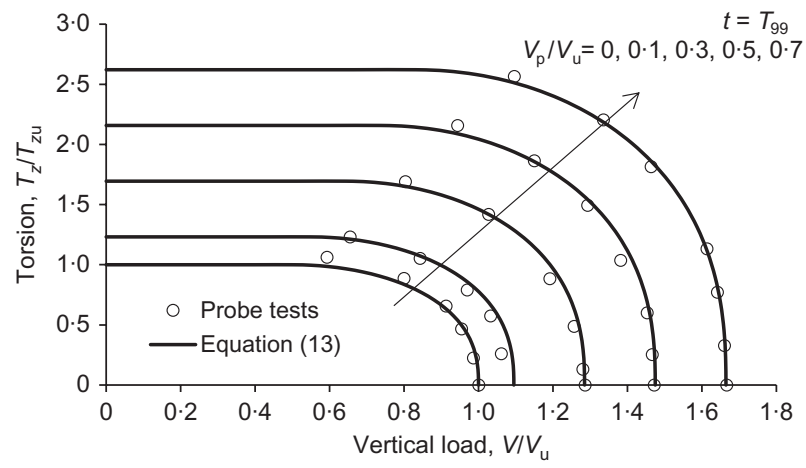

(a)

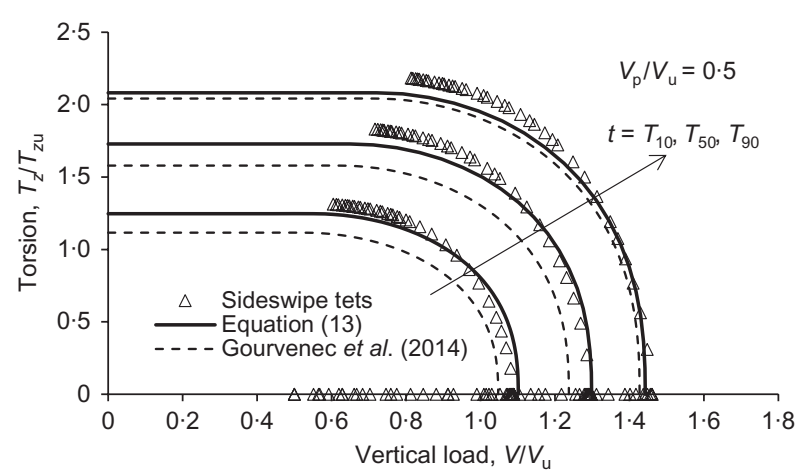

(b)

Fig. 13. Failure envelopes for combined $V-T_{z}$ loading: (a) effect of magnitude of preloading; (b) effect of duration of preloading

\section{Resultant horizontal and moment capacity}

External loads transferred to a mudmat are generally in six degrees of freedom, as depicted in Fig. 1, and the resultant horizontal load or moment is not always parallel to the short or long edge of the foundation. A schematic representation of 
resultant horizontal and moment loading combinations is presented in Fig. 14. For a resultant horizontal load applied in a given direction, $\theta$, the corresponding resultant horizontal capacity, denoted as $H_{\mathrm{u}, \mathrm{cons}}$, can be explored on failure envelopes for combined biaxial horizontal loading. Horizontal capacity of a surface foundation involves a sliding failure mechanism. For a surface foundation, the consolidated, undrained horizontal capacity can be determined theoretically from the operative shear strength immediately beneath the foundation and the area of foundation base, irrespective of the direction in which the foundation slides. Therefore, the failure envelope in the $H_{x}-H_{y}$ plane should theoretically be circular, as for the undrained response. The normalised failure envelopes in biaxial horizontal load space are shown in Fig. 15 and can be described by

$$
\left(\frac{H_{x}}{H_{x \mathrm{u}, \text { cons }}}\right)^{2}+\left(\frac{H_{y}}{H_{y \mathrm{u}, \mathrm{cons}}}\right)^{2}=1
$$

The resultant moment capacity, $M_{\mathrm{u}, \mathrm{cons}}$, for a given loading direction, $\theta_{\mathrm{m}}$, can be determined similarly on the plot of failure envelopes for biaxial moment (Fig. 16). A generalised form for normalised $M_{y}-M_{x}$ failure envelopes may be expressed as

$$
\left(\frac{M_{x}}{M_{x \mathrm{u}, \mathrm{cons}}}\right)^{3-0 \cdot 1 \kappa_{\mathrm{su}}}+\left(\frac{M_{y}}{M_{y \mathrm{u}, \mathrm{cons}}}\right)^{1 \cdot 5}=1
$$

\section{Combined $\mathrm{M}-\mathrm{H}$ load capacity}

Analyses were carried out to investigate the $M-H$ failure envelopes across the range of relative preload $V_{\mathrm{p}} / V_{\mathrm{u}}=0 \cdot 1-0 \cdot 7$, and duration of consolidation corresponding to various degrees of consolidation $\left(t=T_{10}, T_{30}, T_{50}, T_{70}\right.$ and $\left.T_{90}\right)$. The resulting failure envelopes were also shown to expand proportionally with consolidation and as such can be approximated by the same form of expression presented by Feng et al. (2014) for unconsolidated, undrained $M-H$ capacity

$$
\begin{aligned}
& \left(\frac{M}{M_{\mathrm{u}, \text { cons }}} \frac{M}{|M|}\right)^{q}\left[1-\alpha \frac{H}{H_{\mathrm{u}, \text { cons }}} \frac{M}{|M|}+\beta\left(\frac{H}{H_{\mathrm{u}, \text { cons }}}\right)^{2}\right] \\
& +\left(\frac{H}{H_{\mathrm{u}, \text { cons }}}\right)^{2}=1
\end{aligned}
$$

where the power $q$, and coefficients $\alpha$ and $\beta$ are functions of the direction of the resultant horizontal loading, and of the soil strength heterogeneity, $\kappa_{\mathrm{su}}$. These fitting expressions can be taken as

$$
\begin{aligned}
& q=3\left(1+\kappa_{\mathrm{su}} / 10\right) \\
& \alpha=0.3\left(3+\frac{\kappa_{\mathrm{su}}}{10}\left(\cos ^{2} \theta-2 \sin ^{2} \theta\right)\right) \\
& \beta=0.09 \kappa_{\mathrm{su}}
\end{aligned}
$$

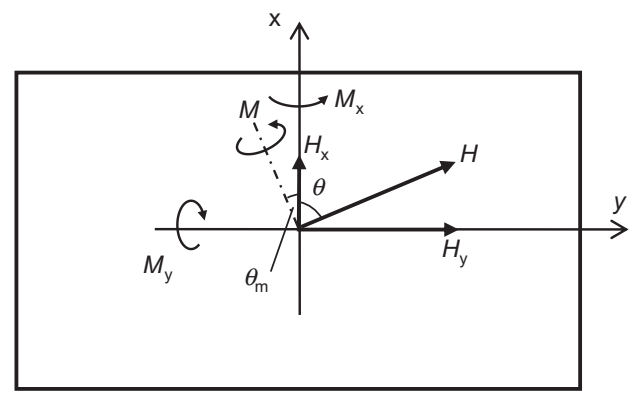

Fig. 14. Resultant horizontal and moment loading

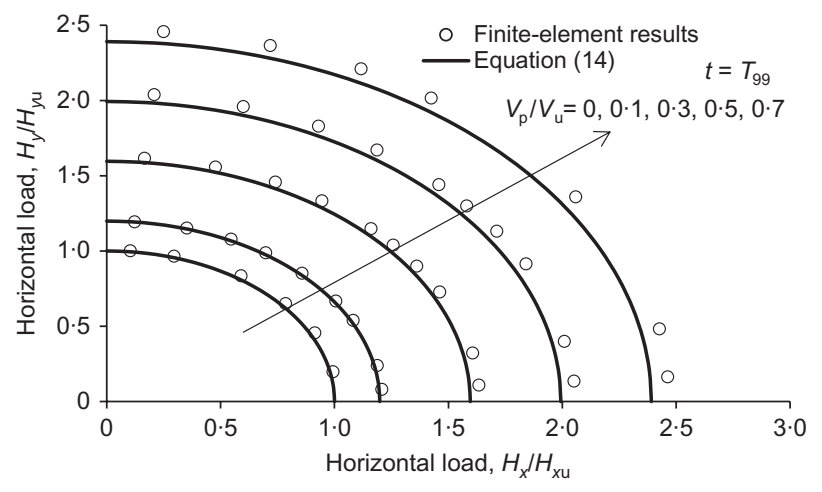

(a)

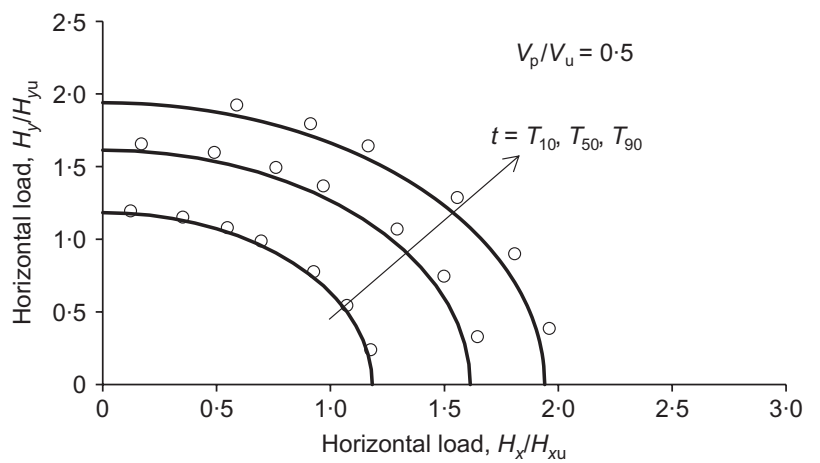

(b)

Fig. 15. Failure envelopes for biaxial horizontal loading: (a) effect of magnitude of preloading; (b) effect of duration of preloading

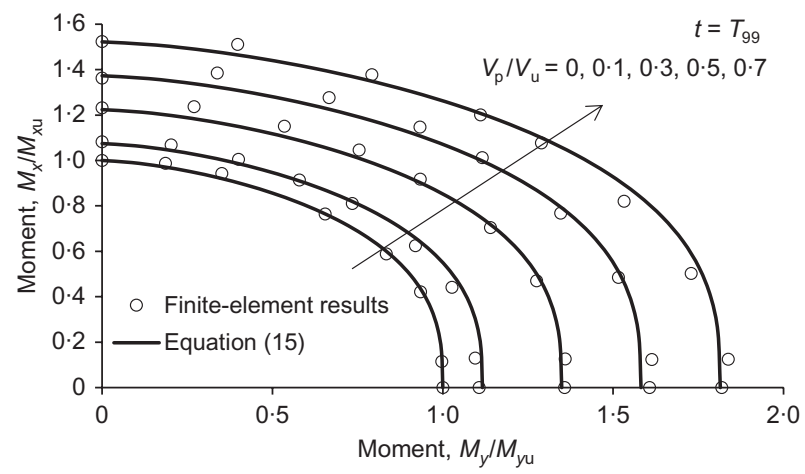

(a)

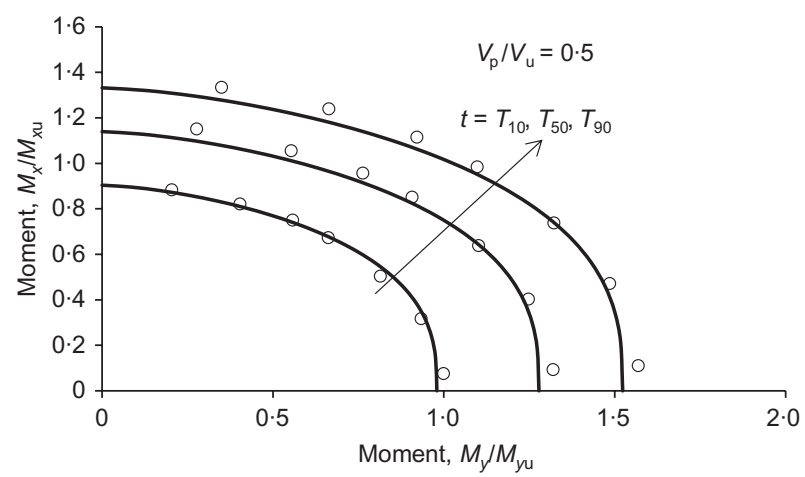

(b)

Fig. 16. Failure envelopes for biaxial moment loading: (a) effect of magnitude of preloading; (b) effect of duration of preloading

Finite-element data for horizontal loading applied parallel to the short edge, $B$, that is at $0^{\circ}$, and parallel to the long edge, $L$, that is at $90^{\circ}$, are plotted in Fig. 17 and Fig. 18 against the predicted failure envelopes for varying magnitude 
and duration of preloading. The results show good agreement for all $H-M$ loading conditions for the cases of relative preload $V_{\mathrm{p}} / V_{\mathrm{u}}<0.5$ but show some over-prediction of the load-carrying capacity for combinations with both positive horizontal loads and moments for higher relative preloads. In practice, the vertical load mobilisation is expected to be less than $50 \%$ and so the loss of accuracy at higher preloads is not considered significant for the proposed applications of the results.

\section{Combined $T_{z}-M-H$ load capacity}

Torsion effectively reduces the maximum horizontal load or moment that can be sustained. Failure envelopes for unconsolidated, undrained $H-T_{z}$ response have been fitted by a general relationship (Finnie \& Morgan, 2004)

$$
\left(\frac{H}{H_{\mathrm{u}}}\right)^{x}+\left(\frac{T_{z}}{T_{z \mathrm{u}}}\right)^{y}=1
$$

This general form of ellipse also yields an accurate fit for the failure envelopes for combined $H-T_{z}$ capacity following consolidation by using the values of the power $x$ and $y$ for unconsolidated, undrained ultimate limit states (Feng et al., 2014). For a surface rectangular foundation, the normalised failure envelopes can be expressed as

$$
\left(\frac{H}{H_{\mathrm{u}, \text { cons }}}\right)^{1.85}+\left(\frac{T_{z}}{T_{z \mathrm{u}, \text { cons }}}\right)^{1.25+0.75(\sin \theta)^{2.5}}=1
$$

Predicted failure envelopes are shown in Fig. 19 compared with the finite-element results for horizontal loading parallel to the short edge $\left(\theta=0^{\circ}\right)$ and long axis $\left(\theta=90^{\circ}\right)$, respectively.

As for the consolidated, undrained response of the foundation, the normalised $M-T_{z}$ failure envelopes are independent of moment direction $\left(\theta_{\mathrm{m}}\right)$. The expression for the $M-T_{z}$ failure envelopes under fully undrained conditions

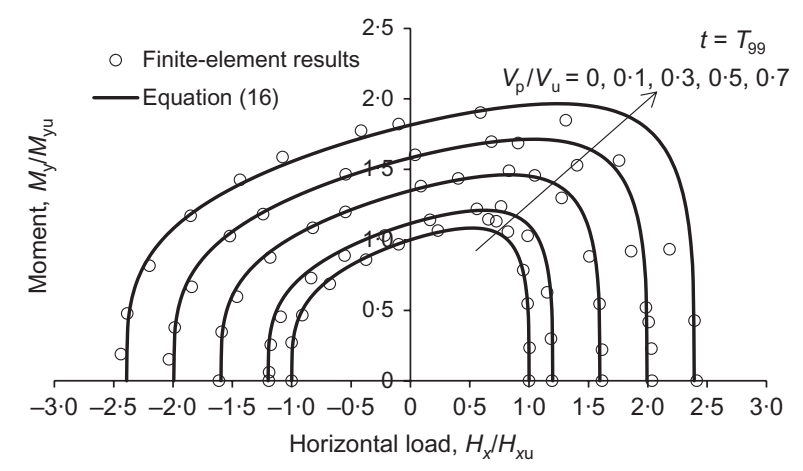

(a)

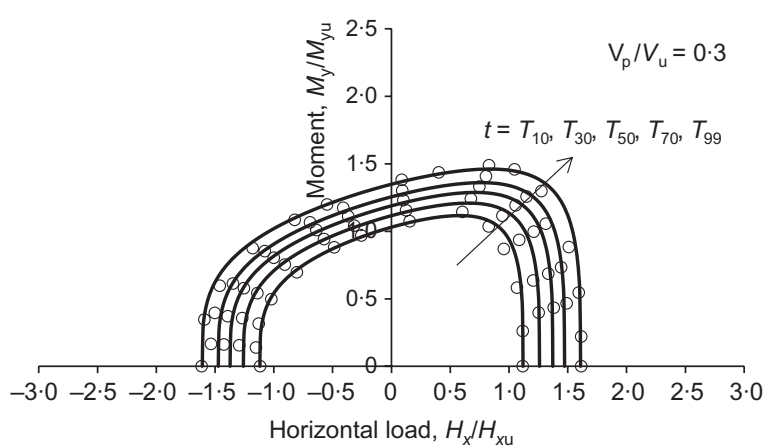

(b)

Fig. 17. Failure envelopes for combined $H_{x}-M_{y}$ loading: (a) effect of magnitude of preloading; (b) effect of duration of preloading

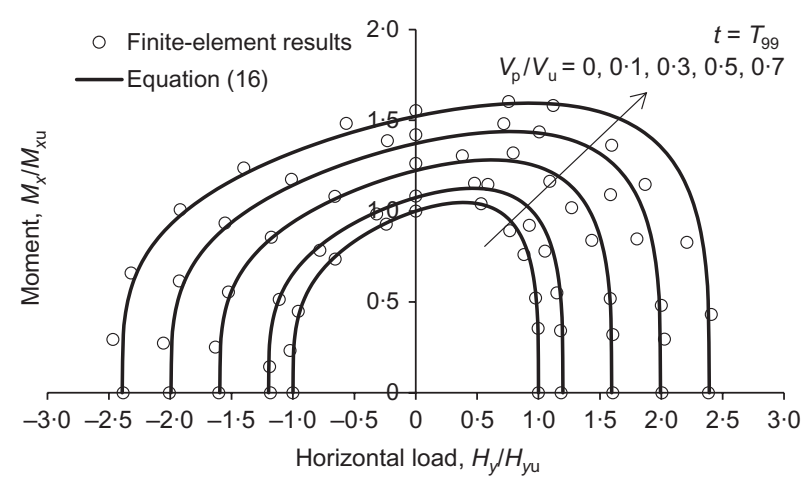

(a)

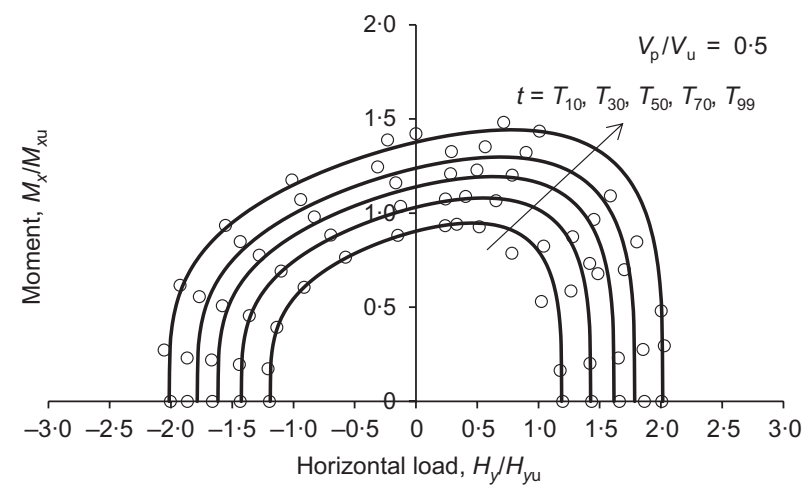

(b)

Fig. 18. Failure envelopes for combined $H_{y}-M_{x}$ loading: (a) effect of magnitude of preloading; (b) effect of duration of preloading

is seen to be applicable for the consolidated, undrained response and the quality of the curve fit is shown in Fig. 20.

$$
\left(\frac{M}{M_{\mathrm{u}, \text { cons }}}\right)^{6}+\left(\frac{T_{z}}{T_{z \mathrm{u}, \text { cons }}}\right)^{2}=1
$$

The failure envelopes expressed by equations (19) and (20) are used to deduce the maximum horizontal load, $H_{\max }$ and moment, $M_{\max }$, corresponding to given mobilised torsion. The $M-H$ failure envelopes accounting for mobilised torsion can be described by equations (16) and (17) by substituting $H_{\mathrm{u}, \text { cons }}$ and $M_{\mathrm{u} \text {,cons }}$ with $H_{\max }$ and $M_{\max }$, respectively. An example of $M-H$ failure envelopes under preloading of $V_{\mathrm{p}} / V_{\mathrm{u}}=0 \cdot 5$, for mobilisation ratios of torsional capacity, $T_{z} / T_{z \mathrm{u}, \text { cons }}=0,0 \cdot 29$ and $0 \cdot 52$ (equivalent to $T_{z} / T_{z \mathrm{u}}=0,0 \cdot 5$ and 0.9 , respectively) is presented in Fig. 21, showing reasonable agreement between the proposed failure envelopes and the finite-element results. The discrepancies for combinations with both positive horizontal loads and moments are attributed to the over-prediction of load-carrying capacity by equation (16), which diminishes with the decreasing $V_{\mathrm{p}} / V_{\mathrm{u}}$ ratio.

\section{Summary of procedure}

The consolidated, undrained load-carrying capacity of surface or shallowly embedded mat foundations resting on a normally consolidated soil, subjected to a given magnitude and duration of preload, can be predicted with the following methodology.

(a) Calculate the unconsolidated undrained uniaxial capacity including $V_{\mathrm{u}}, H_{x \mathrm{u}}, H_{y \mathrm{u}}, M_{y \mathrm{u}}, M_{x \mathrm{u}}$ and $T_{z \mathrm{u}}$, for a given foundation geometry and in situ shear strength profile.

(b) Calculate the relative preload, $V_{\mathrm{p}} / V_{\mathrm{u}}$. 


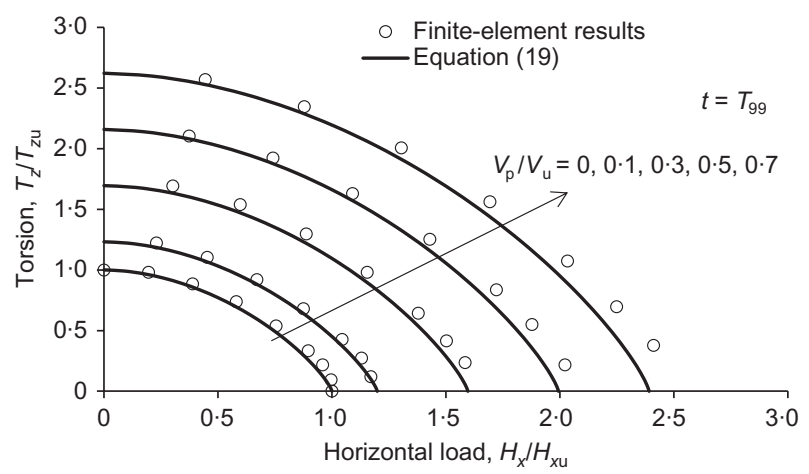

(a)

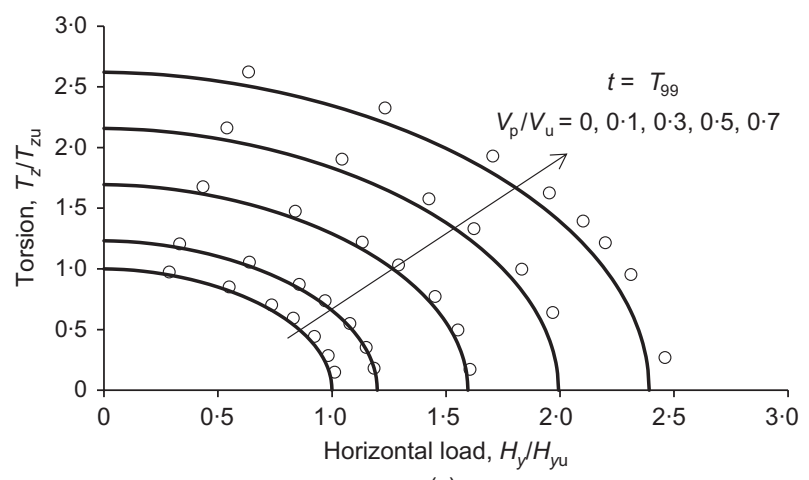

(c)

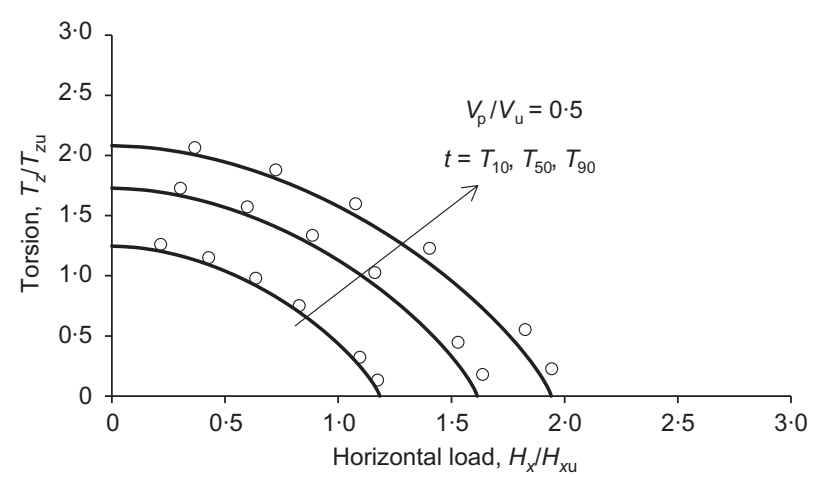

(b)

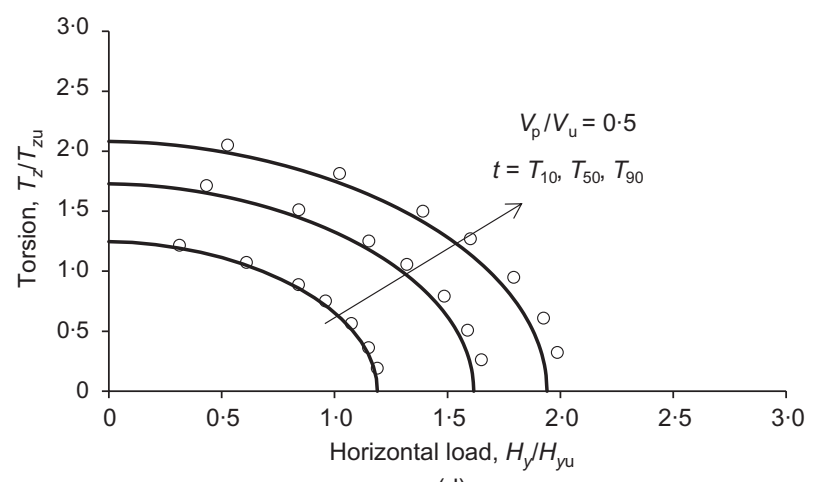

(d)

Fig. 19. Failure envelopes for combined $H-T_{z}$ loading: (a) effect of magnitude of preloading, $H_{x}-T_{z}$; (b) effect of duration of preloading, $H_{x}-T_{z}$; (c) effect of magnitude of preloading, $H_{y}-T_{z}$; (b) effect of duration of preloading, $H_{y}-T_{z}$

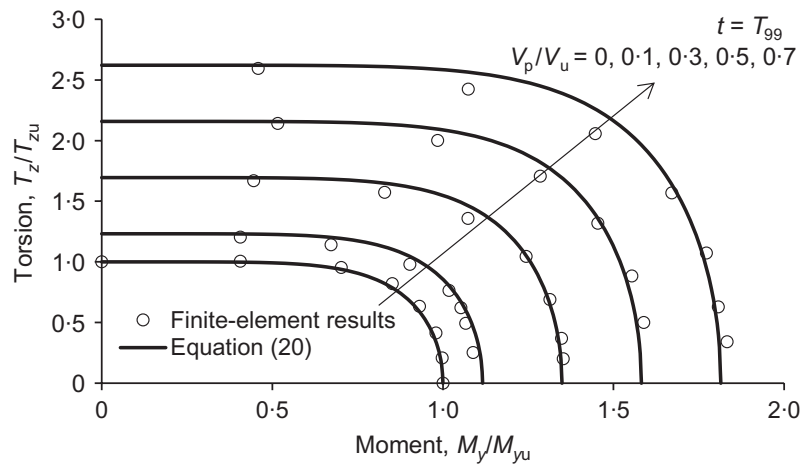

(a)

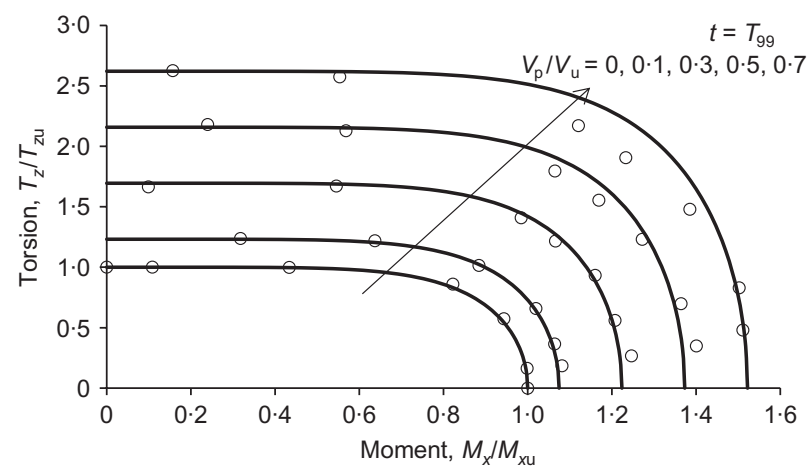

(b)

Fig. 20. Failure envelopes for combined $M-T_{z}$ loading with varying preloads: (a) combined $M_{y}-T_{z}$ loading; (b) combined $M_{x}-T_{z}$ loading

(c) Assess the unconsolidated undrained uniaxial capacity including $H_{x 0}, H_{y 0}, M_{x 0}, M_{y 0}$ and $T_{z 0}$, for load mobilisations, $V_{\mathrm{p}} / V_{\mathrm{u}}$ from the initial failure envelopes

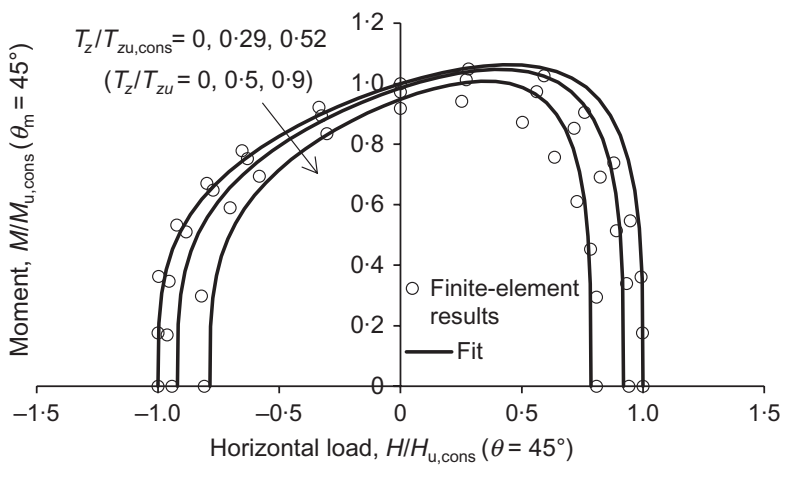

Fig. 21. Failure envelopes for $H-M$ loading for varying torsion

for $V-H_{x}, V-H_{y}, V-M_{y}, V-M_{x}$ and $V-T_{z}$. Refer to equations (10), (11), (12) and (13).

(d) Predict the maximum gain in the uniaixal capacity $\left(V_{\mathrm{u}, \text { cons_max }}, H_{x \mathrm{u} \text {,cons_max }}, H_{y \mathrm{u} \text {,cons_max }}, M_{y \mathrm{u}, \mathrm{cons} \_\max }\right.$, $M_{x \mathrm{u} \text {, cons_max }}$ and $\left.T_{z \mathrm{u}, \text { cons_max }}\right)$ after completion of full primary consolidation (equations (4) and (5) using factors in Table 2).

(e) Calculate the time factor $T$ (equation (7)) associated with the period of consolidation based on the in situ coefficient of consolidation, and calculate the degree of consolidation $U$ using the time factor $T$ (equation (8)).

( $f$ ) Calculate the undrained uniaixal capacity due to partial consolidation, including $V_{\mathrm{u}, \text { cons }}, H_{x \mathrm{u}, \mathrm{cons}}, H_{y \mathrm{u}, \mathrm{cons}}$, $M_{x \mathrm{u}, \mathrm{cons}}, M_{y \mathrm{u}, \mathrm{cons}}$ and $T_{\mathrm{u}, \mathrm{cons}}$ from the corresponding maximum gain (from step $(d)$ ) and the degree of consolidation (from step (e)), using equation (9) with factors listed in Table 3.

(g) For given angle of resultant horizontal load, evaluate corresponding consolidated, undrained horizontal capacity (equation (14)), and similarly for consolidated moment capacity (equation (15)). 
Table 4. Predicted gains in capacity for design example

\begin{tabular}{l|c|c}
\hline Gain & $\begin{array}{c}t=0 \cdot 25 \text { years } \\
U \sim 40 \%\end{array}$ & $\begin{array}{c}t=0 \cdot 5 \text { years } \\
U \sim 60 \%\end{array}$ \\
\hline$V_{\mathrm{u}, \mathrm{cons}} / V_{\mathrm{u}}: \%$ & 118 & 123 \\
$H_{x \mathrm{u}, \mathrm{cons}} / H_{x 0}: \%$ & 137 & 148 \\
$H_{x \mathrm{u}, \mathrm{cons}} / H_{y 0}: \%$ & 137 & 148 \\
$M_{x \mathrm{u}, \mathrm{cons}} / M_{x 0}: \%$ & 118 & 124 \\
$M_{y \mathrm{u}, \mathrm{cons}} / M_{y 0}: \%$ & 123 & 131 \\
$T_{z \mathrm{u}, \mathrm{cons}} / T_{z 0}: \%$ & 144 & 156 \\
\hline
\end{tabular}

(h) Evaluate the $M-H$ load-carrying capacity associated with the mobilised torsional capacity, $T_{z} / T_{z \mathrm{u} \text {,cons }}$ (equations (16)-(20)).

\section{Design example}

An example application is included here to illustrate potential gains in mudmat capacity for typical field conditions. A rectangular mudmat, $5 \mathrm{~m}$ by $10 \mathrm{~m}$, under an operative vertical preload, $V_{\mathrm{p}} / V_{\mathrm{u}}=0 \cdot 35$, resting on a soft, normally consolidated clay with representative coefficient of consolidation of the seabed $c_{\mathrm{v} 0}=3 \mathrm{~m}^{2} /$ year is considered. Durations of consolidation under the vertical preload of 3 months and 6 months are considered. The predicted gains in uniaxial capacities are summarised in Table 4. A 3-month period of consolidation, in practice, the lag between installation and operation of the pipeline, allows a degree of consolidation $U \sim 40 \%$. The uniaxial horizontal capacity $H_{y \mathrm{u}, \text { cons }}$ (parallel to the long axis of the foundation and typically the axis of pipe), the associated moment capacity, $M_{x \mathrm{u}, \mathrm{cons}}$, and torsional capacity, $T_{z \mathrm{u}, \mathrm{cons}}$ increase by $38 \%$, $20 \%$ and $44 \%$, compared with the unconsolidated, undrained capacity, respectively. If the time lag between installation and operation were 6 months, the degree of consolidation would increase to $U \sim 60 \%$ and the corresponding enhancement in horizontal, moment and torsional capacity would increase to $48 \%, 24 \%$ and $56 \%$, respectively. Reliance on consolidated, undrained soil shear strength in predicting undrained capacity of mat foundations clearly offers an opportunity for efficiencies in footprint size or for greater operational loads to be resisted by foundations.

\section{CONCLUSIONS}

A systematic and comprehensive study of consolidated, undrained capacity of rectangular mat foundations under loading in six degrees of freedom, based on thousands of three-dimensional finite-element analyses, has been presented. Uniaxial and combined load capacities have been presented in dimensionless form as a function of relative preload and degree of consolidation. The results have shown that the normalised, consolidated, undrained failure envelope can be derived from simple scaling of the unconsolidated, undrained envelope by the consolidated, undrained uniaxial capacities as a function of relative preload and degree of consolidation.

The design scenario considered in this study enables self-weight consolidation of the supporting soil during the time lag between installation of the mat foundation and operation of the attached pipelines, and hence application of the operational, $H-M-T_{z}$, loading. Reliance on the consolidated shear strength of the soil in the design of the operational performance of the foundation can lead to larger loads being tolerated for a given foundation footprint or foundation sizes to be reduced for given loads. This is of significant interest in engineering practice, as handling limits of pipe-laying vessels are increasingly exceeded with mat foundations designed by traditional methods and relying on in situ strength data.

This paper provides a methodology for predicting the consolidated, undrained response of subsea rectangular mat foundations, resting on soft clay and subjected to general loading in six degrees of freedom. A set of expressions has been set out that enables prediction of uniaxial and combined load capacity as a function of the magnitude of relative preload, degree of consolidation and component loading direction, based on a theoretical critical state soil mechanics framework. The theoretical framework has been shown to be applicable to a practical range of material parameter values. In other words, the scaling parameters $f_{a} f_{\text {su }}$, derived from this study are equally applicable to any MCC soil, not just to the kaolin that formed the basis of the main study presented here. The approximating expressions are well suited to implementation into an automated calculation tool, providing accessible insights into how independent design inputs affect design output and enabling optimisation of a foundation design in terms of foundation geometry, load components or load and material factors.

\section{ACKNOWLEDGEMENTS}

This work forms part of the activities of the Centre for Offshore Foundation Systems (COFS), currently supported as a node of the Australian Research Council Centre of Excellence for Geotechnical Science and Engineering and as a Centre of Excellence by the Lloyd's Register Foundation. Lloyd's Register Foundation helps to protect life and property by supporting engineering-related education, public engagement and the application of research. The work presented in this paper is supported through ARC grant (DP140100684). This support is gratefully acknowledged.

\section{NOTATION}

$A$ bearing area of rectangular mat foundation

$B$ foundation breadth

$c_{\mathrm{v} 0}$ in situ coefficient of consolidation

$e_{0}$ initial void ratio

$e_{\mathrm{cs}}$ void ratio at $p^{\prime}=1 \mathrm{kPa}$ on $\mathrm{CSL}$

$f_{\sigma}$ stress factor

$f_{\text {su }}$ shear strength factor

$H_{x}, H_{y}$ horizontal load along $x$ - and $y$-axis

$H_{\mathrm{x} 0}, H_{\mathrm{y} 0}$ horizontal capacity along $x$ - and $y$-axis accounting for $V_{\mathrm{p}} / V_{\mathrm{u}}$

$H_{x \mathrm{u}}, H_{y \mathrm{u}}$ unconsolidated undrained horizontal load along $\mathrm{x}$ - and $\mathrm{y}$-axis

$H_{x \mathrm{u} . \mathrm{cons}}, H_{y \mathrm{u}, \mathrm{cons}} \quad$ consolidated undrained horizontal load along $x$ - and $y$-axis

$H_{x u . c o n s \_m a x}, \quad$ consolidated undrained horizontal load along

$H_{y u \text {,cons_max }} x$ - and $y$-axis after fully primary consolidation

$K_{0} \quad$ coefficient of earth pressure at rest

$k$ soil permeability

$L$ foundation length

$M_{q}$ slope of the CSL in the $q-p^{\prime}$ plane

$M_{x}, M_{y}$ moment along $x$ - and $y$-axis

$M_{x 0}, M_{y 0}$ moment capacity along $x$ - and $y$-axis accounting for $V_{\mathrm{p}} / V_{\mathrm{u}}$

$M_{x \mathrm{u}}, M_{y \mathrm{u}}$ unconsolidated undrained moment capacity about $x$ - and $y$-axis

$M_{x \mathrm{u} \text {,cons }}, M_{y, \text { cons }}$ consolidated undrained moment capacity about $x$ - and $y$-axis

$M_{x u \text {,cons max }}, \quad$ consolidated undrained moment capacity

$M_{y, \text { cons_max }}$ about $x$ - and $y$-axis after full primary consolidation

$N_{\mathrm{cv}} \quad$ unconsolidated undrained vertical bearing capacity factor

$p^{\prime}$ mean effective stress

$q$ shear stress 
$R$ normally consolidated undrained shear strength ratio

$s_{\mathrm{u}} \quad$ soil undrained shear strength

$s_{\text {um }} \quad$ undrained strength at mudline level

$T$ dimensionless time factor

$T_{z}$ torsion

$T_{z 0}$ torsional capacity accounting for $V_{\mathrm{p}} / V_{\mathrm{u}}$

$T_{z \mathrm{u}}$ unconsolidated undrained torsional capacity

$T_{z \mathrm{u}, \text { cons }}$ consolidated undrained torsional capacity

$T_{z \mathrm{u} \text {, cons_max }}$ consolidated undrained torsional capacity after full primary consolidation

$t$ consolidation time

$U$ degree of consolidation

$V$ vertical load

$V_{\mathrm{p}} \quad$ vertical preload

$V_{\mathrm{u}}$ unconsolidated, undrained vertical capacity

$V_{\mathrm{u}, \mathrm{cons}}$ consolidated undrained vertical capacity

$V_{\text {u,cons_max }}$ consolidated undrained vertical capacity after full primary consolidation

$w$ consolidation settlement

$w_{\mathrm{f}} \quad$ settlement after full primary consolidation

$\alpha, \beta$ curve-fitting factors

$\gamma^{\prime}$ effective unit weight

$\gamma_{\mathrm{w}}$ unit weight of pore water

$\Delta s_{\mathrm{u}} \quad$ change in shear strength due to preload

$\Delta \sigma_{\mathrm{pl}}^{\prime} \quad$ incremental plastic stress

$\Theta \quad$ Lode's angle

$\theta$ direction of resultant horizontal load

$\theta_{\mathrm{m}} \quad$ direction of resultant moment

$\kappa$ recompression index

$\kappa_{\mathrm{su}}$ soil heterogeneity factor $\left(\rho B / s_{\mathrm{u} 0}\right)$

$\lambda$ virgin compression index

$v^{\prime}$ Poisson ratio

$\rho$ undrained shear strength gradient

$\sigma_{\mathrm{v}}^{\prime} \quad$ vertical effective stress

$\phi^{\prime} \quad$ critical state angle of shearing resistance

\section{REFERENCES}

API (2011). RP 2GEO geotechnical and foundation design considerations, 1st edn. Washington, DC, USA: American Petroleum Institute.

Booker, J. R. \& Small, J. C. (1986). The behavior of an impermeable flexible raft on a deep layer of consolidating soil. Int. J. Numer. Analyt. Methods Geomech. 10, No. 3, 311-327.

Bransby, M. (2002). The undrained inclined load capacity of shallow foundations after consolidation under vertical loads. In Numerical models in geomechanics: proceedings of the 8th international symposium NUMOG VIII (eds G. S. Pande and S. Pietruszczak), pp. 431-437, London, UK: CRC Press.

Bransby, M. F. \& Randolph, M. F. (1998). Combined loading of skirted foundations. Géotechnique 48, No. 5, 637-655, http:// dx.doi.org/10.1680/geot.1998.48.5.637.

Chatterjee, S., Gourvenec, S. \& White, D. J. (2014). Assessment of the consolidated breakout response of partially embedded subsea pipelines. Géotechnique 64, No. 5, 391-399, http://dx. doi.org/10.1680/geot.13.P.215.

Dassault Systèmes (2010). Abaqus analysis users' manual. Providence, RI, USA: Simulia Corp.

Davis, E. H. \& Poulos, H. G. (1968). The use of elastic theory for settlement prediction under three-dimensional conditions. Géotechnique 18, No. 1, 67-91, http://dx.doi.org/10.1680/geot. 1968.18.1.67.

Feng, X., Randolph, M. F., Gourvenec, S. \& Wallerand, R. (2014). Design approach for rectangular mudmats under fully three-dimensional loading. Géotechnique 64, No. 1, 51-63, http://dx.doi.org/10.1680/geot.13.P.051.

Finnie, I. M. S. \& Morgan, N. (2004). Torsional loading of subsea structures. Proceedings of the 14th international offshore and polar engineering conference, pp. 326-333. Toulon, France: International Society of Offshore and Polar Engineers (ISOPE).

Gourvenec, S. \& Randolph, M. (2003). Effect of strength nonhomogeneity on the shape of failure envelopes for combined loading of strip and circular foundations on clay. Géotechnique 53, No. 6, 575-586, http://dx.doi.org/10.1680/geot.2003.53. 6.575 .

Gourvenec, S. \& Randolph, M. F. (2010). Consolidation beneath circular skirted foundations. Int. J. Geomech. 10, No. 1, 22-29.

Gourvenec, S. M., Vulpe, C. \& Murthy, T. G. (2014). A method for predicting the consolidated undrained bearing capacity of shallow foundations. Géotechnique 64, No. 3, 215-225, http:// dx.doi.org/10.1680/geot.13.P.101.

ISO (2003). ISO 19901-4: Petroleum and natural gas industries specific requirements for Offshore Structures - Part 4: Geotechnical and foundation design considerations, 1st edn. Geneva, Switzerland: International Standards Organisation.

Manoharan, N. \& Dasgupta, S. (1995). Consolidation analysis of elasto-plastic soil. Comput. Structs 54, No. 6, 1005-1021.

Murff, J. D., Aubeny, C. P. \& Yang, M. (2010). The effect of torsion on the sliding resistance of rectangular foundations. In Frontiers in offshore geotechnics II (eds S. Gourvenec and D. White), pp. 439-443. London, UK: CRC Press.

Nazem, M., Sheng, D., Carter, J. P. \& Sloan, S. W. (2008). Arbitrary Lagrangian-Eulerian method for large-strain consolidation problems. Int. J. Numer. Analyt. Methods Geomech. 32, No. 9, 1023-1050.

Potts, D. M. \& Zdravkovic, L. (1999). Finite element analysis in geotechnical engineering - theory. London, UK: Thomas Telford.

Roscoe, K. H. \& Burland, J. B. (1968). On the generalized stress-strain behaviour of wet clay. In Engineering plasticity (eds J. Heymen and F. A. Leckie), pp. 535-609. Cambridge, UK: Cambridge University Press.

Sloan, S. W. \& Abbo, A. J. (1999). Biot consolidation analysis with automatic time stepping and error control: part 2: applications. Int. J. Numer. Analyt. Methods Geomech. 23, No. 6, 493-529.

Stewart, D. P. (1992). Lateral loading of piled bridge abutments due to embankment construction. PhD thesis, The University of Western Australia, Crawley, Australia.

Taiebat, H. A. \& Carter, J. P. (2000). Numerical studies of the bearing capacity of shallow foundations on cohesive soil subjected to combined loading. Géotechnique 50, No. 4, 409-418, http://dx.doi.org/10.1680/geot.2000.50.4.409.

Tan, F. S. C. (1990). Centrifuge and theoretical modelling of conical footings on sand. $\mathrm{PhD}$ thesis, Cambridge University, Cambridge, UK.

Tani, K. \& Craig, W. H. (1995). Bearing capacity of circular foundations on soft clay of strength increasing with depth. Soils Found. 35, No. 4, 21-35.

Taylor, P. W. \& Oort, T. A. (1971). The increase in bearing capacity resulting from consolidation. Géotechnique 21, No. 4, 376-390, http://dx.doi.org/10.1680/geot.1971.21.4.376.

Vulpe, C. \& White, D. J. (2014). Effect of prior loading cycles on vertical bearing capacity of clay. Int. J. Phys. Modelling Geotech. 14, No. 4, 88-98, http://dx.doi.org/10.1680/ijpmg.14. 00013.

Zdravkovic, L., Potts, D. \& Jackson, C. (2003). Numerical study of the effect of preloading on undrained bearing capacity. Int. J. Geomech. 3, No. 1, 1-10. 